\title{
FERNAND BRAUDEL, LA CIVILIZACIÓN Y LA LARGA DURACIÓN
}

\author{
Por \\ JUAN RAMÓN GOBERNA FALQUE
}

\begin{abstract}
RESUMEN
En este artículo se analizan los vínculos epistemológicos existentes entre el concepto braudeliano de «longue durée» y su particular interpretación de la historia de las civilizaciones. El trabajo consta de tres epígrafes: «Continuidad y discontinuidad de las civilizaciones»; «Uniformidad y diversidad de las civilizaciones» (en donde se presta especial atención a las reflexiones de Fernand Braudel en torno a la civilización industrial, las civilizaciones nacionales o la civilización marxista) y «El triple mecanismo de la definición braudeliana de civilización: el área cultural, el préstamo y la repulsa». En el balance final el autor del artículo asegura que el concepto de civilización oculta tras de sí una estructura catóptrica que hace que la imagen difusa del historiador aparezca siempre reflejada y que Braudel, en este sentido, no constituyó una excepción.
\end{abstract}

\section{PALABRAS CLAVE}

Teoría de la historia, Historiografía francesa, Fernand Braudel, Civilización (concepto), Larga duración (concepto).

«CUADERNOS DE ESTUDIOS GALLEGOS», Tomo L, Fascículo 116, Santiago 2003. 


\begin{abstract}
In this article we analyze the epistemologic bonds between the braudelian concept of longue durée and its particular interpretation of the history of civilizations. The work consists of three epigraphs: «Continuity and discontinuity of the civilizations»; "Uniformity and diversity of civilizations» (where we pay special attention to the reflections of Fernand Braudel around the industrial civilization, the national civilizations or the Marxist civilization) and "The triple mechanism of the braudelian definition of civilization: the cultural area, the loan and the repulse». In the final balance the author of this article assures that the concept civilization hides itself one catoptric structure that makes the diffuse image of the historian always appear reflected and, in this sense, Braudel did not constitute an exception.
\end{abstract}

\title{
KEYWORDS
}

Theory of History, French Historiography, Fernand Braudel, Civilization (concept), Long duration (concept).

Lo que el historiador de las civilizaciones puede afirmar, mejor que cualquier otro, es que las civilizaciones son realidades de muy larga duración' 1 .

Uno de los legados teóricos y metodológicos más conocidos y discutidos de la obra de Fernand Braudel es el concepto de «longue durée»². En este trabajo nos ocuparemos particularmente del estudio de la vincula-

\footnotetext{
${ }^{1}$ F. Braudel, «Aportación de la historia de las civilizaciones», La Historia y las ciencias sociales, Madrid, Alianza Editorial, 1968, p. 187.

${ }^{2}$ En los últimos años han sido publicados un buen número de libros sobre la obra y las aportaciones metodológicas de Braudel. Entre los más importantes están los que a continuación se recogen, ordenados siguiendo el criterio cronológico del año de publica-
}

«CUADERNOS DE ESTUDIOS GALLEGOS», Tomo L, Fascículo 116, Santiago 2003. 
ción de esta idea con el concepto de civilización, aspecto especialmente importante si tenemos en cuenta las siguientes observaciones del propio Braudel: «Lo que quizá conozcamos mejor que cualquier otro observador de lo social es la fundamental diversidad del mundo. Todos nosotros sabemos que toda sociedad, todo grupo social, participan en alto grado, con relaciones íntimas o lejanas, en una civilización, o más exactamente, en una serie de civilizaciones superpuestas, mutuamente vinculadas y a veces muy dispares; y que cada una de ellas y su conjunto nos introduce en un movimiento histórico inmenso, de muy larga duración, que constituye para cada sociedad el manantial de una lógica interna, que le es propia, y de innumerables contradicciones $»^{3}$.

ción: Mélanges en l'honneur de Fernand Braudel, Toulouse, Privat, 1973 (vol. I: Histoire économique du monde méditerranéen (1450-1650) y vol. II: Méthodologie de l'histoire et des sciences humaines); Maurice Aymard, Alain Caillé, François Dosse, François Fourquet et al., Lire Braudel, París, La Découverte, 1988; Bianca Arcangeli y Giovanni Muto (eds.), Fernand Braudel: il mestiere di uno storico, Nápoles, Ed. scientifiche italiane, 1988; Barbara Kronsteiner, Zeit, Raum, Struktur: Fernand Braudel und die Geschichtsschreibung in Frankreich, Viena, Geyer-Edition, 1989; Yves Lacoste, Paysages politiques: Braudel, Gracq, Reclus, París, Librairie générale française, 1990; François-Xavier Verschave, Libres leçons de Braudel: passarelles pour une société non excluante, París, Syros, 1994; Pierre Daix, Braudel, París, Flammarion, 1995; Ruggiero Romano, Braudel e noi: riflessioni sulla cultura storica del nostro tempo, Roma, Donzelli, 1995; Giuliana Gemelli, Fernand Braudel, París, O. Jacob, 1995; Carlos A. Aguirre Rojas, Fernand Braudel y las ciencias humanas, Barcelona, Montesinos, 1996; Stuart Clark (ed.), Fernand Braudel, vol. III de la obra The Annales school: critical assessments, Londres, Nueva York, Rouletge, 1999; Jacques Revel (ed.), Fernand Braudel et l'histoire, París, Hachette, 1999; Roselyne de Ayala y Paule Braudel (eds.), Les ambitions de l'histoire, París, Librairie générale française, 1999; Carlos A. Aguirre Rojas, Breves ensayos críticos, Morelia, Morelia, 2000; Carlos A. Aguirre Rojas, Ensayos braudelianos: itinerarios intelectuales y aportes historiográficos de Fernand Braudel, México, Asociación nacional de profesores de historia de México - Rosario, Prohistoria, 2000; Alain Brunhes, Fernand Braudel: synthèse et liberté, París, J. Lyon, 2001; Paul Carmignani (dir.), Autour de F. Braudel, Perpignan, Presses universitaires de Perpignan, 2002.

${ }^{3}$ F. Braudel, «Aportación de la historia de las civilizaciones», La Historia y las ciencias sociales, op. cit., p. 186. Sobre este tema, $c f$. J. R. Goberna Falque, Civilización. Historia de una idea, Santiago de Compostela, Servicio de Publicacións da Universidade, 1999.

«CUADERNOS DE ESTUDIOS GALLEGOS», Tomo L, Fascículo 116, Santiago 2003. 


\section{CONTINUIDAD Y DISCONTINUIDAD DE LAS CIVILIZA- CIONES}

Frente a las afirmaciones de filósofos de la historia como Oswald Spengler o Arnold J. Toynbee ${ }^{4}$, Braudel afirma que las civilizaciones «no son 'mortales', sobre todo a escala de nuestra vida individual, a pesar de la frase demasiado célebre de Paul Valéry. Quiero decir que los accidentes mortales, si existen -y existen, claro está, e incluso son capaces de dislocar sus constelaciones fundamentales-, les afectan infinitamente menos de lo que con frecuencia se cree. En muchos casos, se trata simplemente de letargos transitorios. Por lo general, sólo son perecederas sus flores más exquisitas, sus éxitos más excepcionales; pero las raíces profundas subsisten a muchas rupturas, a muchos inviernos $»^{5}$.

\subsection{La longevidad de las civilizaciones}

Las civilizaciones, realidades de larga, de inagotable duración, readaptadas sin fin a su destino, sobrepasarían en longevidad, pues, según Braudel, a todas las demás «realidades colectivas» y les sobrevivirían. Del mismo modo que en el espacio rebasan los límites de las sociedades precisas (que se verían así sumidas en su mundo por lo general más amplio que ellas y que recibirían de él, sin ser conscientes de ello, un impulso o impulsos particulares), así en el tiempo se afirmaría a su favor un exceso, que les transmitiría extrañas herencias, incomprensibles para quien se contenta con observar, con conocer al «presente» en el sentido más reducido de la palabra. Dicho de otra forma, «las civilizaciones sobreviven a las conmociones políticas, sociales, económicas y hasta ideológicas, que, por lo demás, son quienes las determinan insidiosa y hasta poderosamente a veces» ${ }^{6}$.

Tampoco acepta Braudel, en lo que a las civilizaciones se refiere, la existencia de rupturas o de catástrofes sociales irremediables. No nos apresuremos, pues, a decir demasiado categóricamente... que la civiliza-

\footnotetext{
${ }^{4}$ Sobre este tema, cf. J. R. Goberna Falque, Civilización. Historia de una idea, Santiago de Compostela, Servicio de Publicacións da Universidade, 1999.

${ }^{5}$ F. Braudel, «Aportación de la historia de las civilizaciones», La Historia y las ciencias sociales, op. cit., p. 187.

${ }^{6}$ Ibid.
}

«CUADERNOS DE ESTUDIOS GALLEGOS», Tomo L, Fascículo 116, Santiago 2003. 
ción francesa es impensable sin una burguesía... Y no obstante, al igual que las demás, la civilización francesa, puede, en último extremo, cambiar de soporte oficial o crearse uno nuevo. Si pierde esta burguesía, es incluso plausible que se asista al nacimiento de otra. Con este motivo, cambiaría todo de color en relación a sí misma, pero conservaría casi todos sus matices o peculiaridades con relación a otras civilizaciones; se mantendría, en suma, en la mayoría de sus 'virtudes' y de sus 'errores'. O, por lo menos, así lo creo» ${ }^{7}$.

Sin embargo, sí que reconoce pequeñas rupturas en el tiempo presente, que tardan mucho tiempo en afirmarse: «Hay que precisar, en primer lugar, qué entendemos por tiempo presente. No debemos juzgarlo a escala de nuestras vidas individuales, tomando como referencia esas fracciones cotidianas tan nimias, insignificantes y traslúcidas que constituyen nuestras existencias personales. A escala de las civilizaciones, e incluso a escala de todo tipo de construcciones colectivas, hay que utilizar, para su comprensión y aprehensión, otras medidas. El presente de la civilización de hoy está constituido por esa enorme masa de tiempo cuyo amanecer estaría señalado por el siglo XVIII y cuya noche no estaría aún próxima. Hacia 1750, el mundo, con sus múltiples civilizaciones, se convirtió en objeto de una serie de conmociones y de catástrofes en cadena (que no constituyen únicamente el patrimonio de la civilización occidental). En ella nos encontramos hoy» ${ }^{8}$.

Esta revolución, estas perturbaciones repetidas, estarían determinadas no sólo por la revolución industrial, sino también por una revolución científica y por una revolución biológica que ha provocado la superpoblación mundial. «De atreverse uno a hablar de movimiento de la historia, nunca podrá hacerse con más propiedad que a propósito de estas mareas conjugadas y omnipresentes. El poder material del hombre levanta al mundo y al hombre, lo arranca a sí mismo, lo empuja hacia una vida inédita. Un historiador habituado a una época relativamente próxima -el siglo XVI, por ejemplo- tiene la sensación, a partir del siglo XVIII, de acceder a un planeta nuevo» ${ }^{9}$.

\footnotetext{
${ }^{7}$ Op. cit., p. 188.

${ }^{8}$ Op. cit., p. 194.

${ }^{9}$ Op. cit., p. 195.
}

«CUADERNOS DE ESTUDIOS GALLEGOS», Tomo L, Fascículo 116, Santiago 2003. 
Por tanto, Braudel está convencido de que el tiempo presente rompe con los viejos ciclos y con las tradicionales costumbres del hombre. Y es que la economía y el número de hombres tienen mucho que decir en la historia de las civilizaciones. "Si me alzo tan vehementemente contra las ideas de Spengler y de Toynbee es porque hacen volver con obstinación a la humanidad a sus antiguos momentos caducados, a lo ya visto. Cuando se acepta que las civilizaciones de hoy repiten el ciclo de la de los incas o de cualquier otra, hay que haber admitido previamente que ni la economía ni la demografía tienen nada que ver con las civilizaciones ${ }^{10}{ }^{0}$

De hecho, el hombre cambiaría el ritmo. Como resultado de ello, la civilización, las civilizaciones (con todas particularidades materiales, espirituales e intelectuales) se ven afectadas. «¿Quién puede prever lo que serán el día de mañana el trabajo humano y su extraño compañero, el ocio, y lo que será su religión, presa entre la tradición, la ideología y la razón?; ¿quién puede prever en qué se convertirán, más allá de las fórmulas actuales, las explicaciones de la ciencia objetiva de mañana, el aspecto que revestirán las ciencias humanas, que todavía hoy se encuentran en la niñez? ${ }^{11}$. Braudel consigue liberarse, de este modo, de uno de los aspectos más falsamente científicos del conocimiento histórico, la capacidad de emitir previsiones de futuro, casi siempre en forma de especulaciones proféticas de apocalipsis inevitables.

\subsection{Las civilizaciones son continuidades}

Ninguna civilización actual, a juicio de Braudel, sería verdaderamente comprensible sin un conocimiento de los itinerarios ya recorridos, de los valores antiguos, de las experiencias vividas. Una civilización es siempre un pasado, de este modo, un cierto pasado vivo. Por consiguiente, la historia de una civilización no sería sino el intento de entresacar de sus coordenadas antiguas las que siguen siendo válidas para la actualidad. «No se trata de exponer todo lo que se sabe de la civilización griega o de la Edad Media, sino todo lo que, de esta vida de antaño, continúa siendo eficaz y activo, hoy día, en la Europa occidental o en la China de Mao

\footnotetext{
${ }^{10}$ Op. cit., p. 196.

${ }^{11}$ Ibid.
}

«CUADERNOS DE ESTUDIOS GALLEGOS», Tomo L, Fascículo 116, Santiago 2003. 
Tsé-Tung, respectivamente. Todo lo que relaciona al pasado con el presente, con frecuencia a siglos y siglos de distancia» ${ }^{12}$.

Cualquier civilización se presentaría, en primer lugar, como una serie de hechos de civilización fáciles de aprehender: una obra de teatro, una exposición de pintura, el éxito de un determinado libro, una filosofía, una indumentaria, un descubrimiento científico, una puesta a punto técnica..., todos ellos, acontecimientos aparentemente independientes los unos de los otros. Estos hechos de civilización tienen siempre una existencia efímera. Esta variabilidad se traduciría en la sucesión de las épocas literarias, artísticas o filosóficas, como el Renacimiento o el Romanticismo, que se reducirían a una serie de episodios cerrados en sí mismos. «Cabe decir, aplicando la terminología de los economistas, que hay coyunturas culturales, lo mismo que hay coyunturas económicas, es decir, fluctuaciones más o menos largas o precipitadas, y que, en la mayoría de los casos, se suceden contraponiéndose violentamente» ${ }^{13}$.

La imagen predominante sería, pues, la de un continuo ir y venir. La civilización braudeliana, lo mismo que una economía, tiene un ritmo propio. La presenta como una historia interrumpida por eclipses, historia que fácilmente puede ser recortada en pedazos sucesivos, que prácticamente se desconocen los unos a los otros. Y, de hecho, se habla del Siglo de Luis $X I V$ o del Siglo de las Luces e, incluso, de «la civilización clásica» y de la «civilización del siglo XVIII». Se trata de «civilizaciones de época». Reconoce Braudel que esta terminología va en contra de la idea misma de civilización, idea que en Braudel supone una continuidad. Sin embargo, siendo consciente de este grave problema, lo resuelve cómodamente, diciéndonos que «no discutiremos esta contradicción, ya que, por otra parte, unidad y diversidad tan pronto se enfrentan como conviven, y tenemos que admitirlo así $\rangle^{14}$. Podemos comprobar que Braudel consigue salvar el concepto, a duras penas, gracias a una definición flotante de civilización.

A esta familia de problemas se añade otra: ¿cómo casa la continuidad histórica de la civilización con la evidente diversidad de la historia evenemencial? $\mathrm{Y}$ es que, en la historia de las civilizaciones ciertos acon-

\footnotetext{
${ }^{12} \mathrm{~F}$. Braudel, Las civilizaciones actuales, Madrid, Tecnos, 1966 (París, 1963), p. 34.

${ }^{13}$ Op. cit., p. 35.

${ }^{14} \mathrm{Ibid}$.
}

«CUADERNOS DE ESTUDIOS GALLEGOS», Tomo L, Fascículo 116, Santiago 2003. 
tecimientos o personajes excepcionales, ocupan un lugar aparte, privilegiado. «En fin de cuentas, las civilizaciones están constituidas por los hombres, y, por lo tanto, por las gestiones, las acciones, los entusiasmos y los «compromisos» de los hombres, y también sus paradójicos cambios en la manera de actuar o de pensar» ${ }^{15}$. Por ello, Braudel opta por realizar una selección: los acontecimientos o los hombres que señalan un «cambio», una fase nueva, destacan por sí mismos. Cuanto más importante es la aportación, más necesaria es la señalización. «Un gran acontecimiento (es decir, rico en consecuencias) fue el descubrimiento de la gravedad universal por Newton en 1687. Pero la primera representación del Cid (1636) o de Hernani (1830) fueron acontecimientos significativos ${ }^{16}$. De la misma manera, sobresalen una serie de hombres, en la medida en que su obra anuncia o resume una etapa histórica. «Este es el caso de Joachim du Bellay (1522-1566) con su Defensa e ilustración de la lengua france$s a$; de Leibnitz (1646-1716), inventor del cálculo infinitesimal, o de Denis Papin (1647-1714), inventor de la máquina de vapor» ${ }^{17}$.

Pero los nombres que verdaderamente dominan la historia de las civilizaciones son los que franquean una serie de coyunturas. «En la conjunción de amplios períodos destacan con frecuencia espíritus privilegiados en los que se encarnan al mismo tiempo varias generaciones: Dante (12651321) al final de la Edad Media «latina»; Goethe (1749-1832), al terminar la primera modernidad europea; añadamos a Newton, en el umbral de la física clásica, o también, aunque agrandado por las dimensiones monstruosas de la ciencia contemporánea, al célebre Albert Einstein (18791955) ${ }^{18}$. Pero a una categoría excepcional pertenecen los creadores de los grandes sistemas de pensamiento: «Sócrates o Platón, Confucio, Descartes o Carlos Marx dominan varios siglos a la vez. Son los fundadores de la civilización, apenas menos importantes que los astros de primera magnitud, fundadores de las religiones: Buda, Cristo, Mahoma, todos ellos sumidos en una iluminación todavía viva» ${ }^{19}$.

${ }^{15}$ Op. cit., p. 35 y s.

${ }^{16}$ Op. cit., p. 36.

${ }^{17}$ Ibid.

${ }^{18} \mathrm{Ibid}$.

${ }^{19} \mathrm{Ibid}$.

«CUADERNOS DE ESTUDIOS GALLEGOS», Tomo L, Fascículo 116, Santiago 2003. 
Sin embargo, habría unas terceras realidades de civilización que duran tanto tiempo que pueden parecer inmutables, aunque también varían lenta e imperceptiblemente. Es el caso de las sujeciones por el medio geográfico, por las jerarquías sociales, por las «psiques» colectivas, por las necesidades económicas, «todas ellas fuerzas profundas $\mathrm{y}$, sin embargo, difícilmente reconoscibles a primera vista, sobre todo para aquellos que viven al mismo tiempo, para quienes aparecen como naturales y sin problemas $»^{20}$. En este mismo sentido, «es evidente que estas permanencias, estas selecciones heredadas o estas denegaciones con respecto a las otras civilizaciones son generalmente inconscientes para la mayoría de los hombres. Y para destacarlas claramente conviene alejarse, por lo menos mentalmente, de la civilización en la que uno mismo se encuentra inmerso» ${ }^{21}$. Braudel, sin embargo, al situarse, como tantos historiadores y filósofos, fuera del tiempo y del espacio, a modo de sujeto cognoscente, asegura poder reconocer estas realidades a las que el conocimiento del resto de los mortales no puede acceder.

Estas realidades las denomina Braudel con el término de «estructuras». "A esa historia profunda la he llamado estructural, pero, por favor, entiéndase de una vez por todas que $m i$ estructuralismo no tiene nada que ver con el estructuralismo (por otro lado pasado de moda) de los lingüistas. Para mí es estructura todo lo que resiste al tiempo de la historia, lo que dura e incluso perdura -por tanto algo muy real, y no la abstracción de la relación o de la ecuación matemática ${ }^{22}$. Llama la atención el énfasis que pone Braudel a la hora de desvincular su concepto de estructura de la de los estructuralistas franceses y el modo de ridiculizarlos (el apelativo más común es el de «pedantes»). Quizá no se trate más que de una carrera de desprestigio hacia la única corriente que ha puesto en peligro la hegemonía annalista en el dominio de las ciencias humanas en Francia. En todo caso, según Braudel, la búsqueda sistemática de estructuras, de aquello que se mantiene de hecho más allá de las tempestades del tiempo corto es el riesgo (necesario) en el que debe incurrir todo historiador. «Lógicamente, en cuanto a mí se refiere, en esta búsqueda necesaria

\footnotetext{
${ }^{20}$ Op. cit., p. 37.

${ }^{21}$ Ibid.

${ }^{22}$ F. Braudel, Escritos sobre la historia, Madrid, Alianza Universidad, 1991 (París, 1990), p. 154.
}

«CUADERNOS DE ESTUDIOS GALLEGOS», Tomo L, Fascículo 116, Santiago 2003. 
de estructuras trataría de construir modelos, es decir, sistemas de explicaciones mutuamente relacionadas. En primer lugar, para una determinada civilización. Después, para otra. Nada nos permite pensar de antemano que todas ellas admitan estructuras semejantes; o, lo que viene a ser lo mismo, que prosigan a lo largo de la historia encadenamientos idénticos. Lo lógico sería más bien lo contrario» ${ }^{23}$.

El historiador no las captaría en seguida en su relato cronológico, demasiado precipitado. Sólo sería posible seguir el rastro de estas realidades en su lentísima evolución si se recorren y se contemplan espacios de tiempo muy amplios. Las coyunturas, los acontecimientos e incluso los hombres se borran, destacando entonces las grandes permanencias o semipermanencias, tanto conscientes como inconscientes. «He aquí los 'fundamentos' o, mejor dicho, 'las estructuras' de las civilizaciones: los sentimientos religiosos, por ejemplo, o bien el inmovilismo de las comunidades campesinas, o las diferentes actitudes ante la muerte, el trabajo, el placer o la vida familiar.... $\rangle^{24}$. Estas realidades, estas estructuras tendrían siempre rasgos distintivos y originales. Serían las que caracterizan y crean a las civilizaciones. $Y$ éstas no las cambian porque las consideran valores insustituibles. La función de la mujer, por ejemplo, es presentada por Braudel como «una estructura de la civilización, como un test, porque es, en cada civilización, una realidad de larga duración, resistente a los empujes exteriores, dificilmente modificable de un día para otro» ${ }^{25}$.

En resumen, y tras realizar una serie de incursiones a través de las resistencias, de las aquiescencias, de las permanencias, de las lentas deformaciones de las civilizaciones (de las que nos ocuparemos más adelante), Braudel formula una definición que devolvería a éstas su aspecto particular y único: «las civilizaciones son continuidades históricas» ${ }^{26}$. En este sentido, la civilización sería la más larga de las historias. Pero el historiador no tendría acceso inmediato a esta verdad: sólo se abriría paso después de observaciones sucesivas, "de la misma manera que, al ascender, el alcance de la vista se va ampliando progresivamente». Como metá-

\footnotetext{
${ }^{23}$ Op. cit., p. 185

${ }^{24}$ Op. cit., p. 37.

${ }^{25}$ Op. cit., p. 37.

${ }^{26}$ Op. cit., p. 41.
} 
fora, podemos dejarnos seducir; pero enseguida comprobaremos la debilidad epistemológica de ese planteamiento.

$Y$ es que esa propuesta metodológica se basa en los diferentes tiempos de la historia que, según Braudel, son inteligibles desde el campo del conocimiento histórico. Se puede asegurar que, junto a la serie de estudios consecutivos a El Mediterráneo, su teoría de las temporalidades ha sido el aspecto teórico más comentado, seguido y criticado de todas las aportaciones de Braudel $^{27}$. En su opinión, la historia trabaja en escalas, en unidades de medida muchas veces diferentes, ya sea día a día, año a año o por decenas de años a la vez, y hasta por siglos. En cada caso, el paisaje varía según la medida adoptada. Las contradicciones entre las realidades observadas, entre estos tiempos de diferente longitud, serían objeto de la dialéctica propia de la historia. El historiador, en su praxis, trabajaría por lo menos en tres planos diferentes. Un primer plano A, el de la historia tradicional, el del relato que enlaza acontecimiento con acontecimiento, como hacía el cronista y lo hace en la actualidad el periodista. Sin embargo, esta historia, que se borraría tan pronto como ha sido leída, «nos deja muchas veces con hambre e incapaces de juzgar y de comprender» ${ }^{28}$. Un segundo plano B reflejaría los episodios considerados en bloque: el Romanticismo, la Revolución Francesa, la Revolución industrial, la Segunda Guerra Mundial. La unidad de medida sería esta vez la decena, la veintena e incluso la cincuentena de años. Y en razón de estos conjuntos -ya se les llame períodos, fases, episodios o coyunturas- serían relacionados e interpretados los hechos y ofrecidas una serie de explicaciones. Se trataría ya de acontecimientos largos, libres de detalles superfluos. Por último, un tercer plano $\mathrm{C}$ desbordaría estos acontecimientos largos y recoge sólo los movimientos seculares o pluriseculares. Estudiaría una historia en la que todos los movimientos son lentos y ocupan grandes espacios de tiempo. Desde este punto de vista, la Revolución Francesa sería sólo un momento, aunque esencial, de la historia del destino revolucionario liberal y violento de Occidente. En este último grado, al que los soció-

\footnotetext{
${ }^{27}$ Cientos de estudios y artículos han procurado desarrollar y comentar esta teoría de las temporalidades, presente a lo largo de toda la obra de Braudel, aunque expuesta de un modo más amplio en su artículo «La larga duración», en: La Historia y las ciencias sociales, op. cit., pp. 60-106.

${ }^{28}$ Op. cit., p. 41.
}

«CUADERNOS DE ESTUDIOS GALLEGOS», Tomo L, Fascículo 116, Santiago 2003. 
logos llamarían «plataforma en profundidad», «las civilizaciones, una vez relegados los accidentes y las peripecias que les han dado color y relieve, aparecen en su longevidad o, si se prefiere, en sus permanencias, sus estructuras, sus esquemas casi abstractos y, sin embargo, fundamentales $)^{29}$. De manera que una civilización no se referiría ni una determinada economía ni una determinada sociedad, sino lo que persiste a través de una serie de economías y de sociedades y lo que se deja desviar a duras penas.

Como afirma José Carlos Bermejo Barrera, «la noción de duración tiene su origen en la filosofía de $\mathrm{H}$. Bergson y es una característica común de todas las filosofías contemporáneas de tipo vitalista: M. Heidegger, J. Ortega $\iota^{30}$. La crítica que expone Bermejo, y que nosotros recogemos, es que la duración de Bergson es una noción aplicable al Hombre o al Sujeto cognoscente porque es el hombre en el desarrollo de su vida el que crea su propia temporalidad, que, naturalmente, está dotada de unos contenidos psicológicos y subjetivos. «Filosóficamente, la noción es discutible. Históricamente es deleznable $»^{31}$.

La razón es muy simple. Si queremos liberar al conocimiento histórico de sus componentes irracionales, lo primero que debemos hacer es despsicologizarlo. Y si afirmamos, en sentido estricto, que la economía rural posee una duración propia, lo que estamos haciendo es convertir una abstracción analítica (la noción de economía rural) en un sujeto dotado de una entidad psicológica suficiente como para crear su propio ritmo vital. Pero, como dice Bermejo, «las abstracciones no tienen vida, sólo viven los hombres, los animales, las plantas. Dar vida a lo que no la tiene es jugar a los dioses creadores, pero, como no somos dioses, cuando jugamos a la creación solemos fabricar a unos seres superiores a nosotros mismos a los que tendemos a divinizar ${ }^{32}$.

Deberíamos limitarnos a analizar y a afirmar, de acuerdo con Braudel, aunque matizando su teoría, que el pasado en sentido unitario no existe. Tampoco existen pasados, sino una serie de hechos y problemas, acontecidas en un tiempo cronológicamente anterior al actual, que sólo son

${ }^{29} \mathrm{Ibid}$.

${ }^{30}$ J. C. Bermejo Barrera, Psicoanálisis del conocimiento histórico, Madrid, Akal, 1983

${ }^{31}$ Op. cit., p. 96 y s.

${ }^{32}$ Op. cit., p. 97.

«CUADERNOS DE ESTUDIOS GALLEGOS», Tomo L, Fascículo 116, Santiago 2003. 
comprensibles si introducimos en su análisis una categoría multifuncional del tiempo. «El tiempo histórico, como el espacio, no existe, no es un dato objetivo, sino un instrumento de análisis que introduce el historiador. Por ello no puede ser considerado unitariamente, sino desde diferentes puntos de vista, de acuerdo con los problemas que se trate de analizar en cada momento ${ }^{33}$. Esto no implicaría que cada tiempo vaya por su lado, porque, al igual que existe una ordenación causal, también existe una estructuración temporal, que es consecuencia de la articulación de las causas. Relativizar el tiempo histórico no supone, por lo tanto, subjetivizarlo, ni tratar de sembrar el caos, sino simplemente intentar construir la Historia de un modo lógico, liberándolo de lo psicológico y de las abstracciones divinizadas.

\subsection{Continuidad histórica y progreso}

A pesar de todas sus precauciones, la civilización braudeliana continúa oscilando entre sus acepciones descriptivas y normativas, ya que no logra librarse de su sentido de etapa ni sus sentidos de ascenso o progreso, y en este caso puede decirse que comparte una de las ideas (falsa idea, como aseguraba Lévi-Strauss) de los adeptos del evolucionismo, la consideración del progreso como algo necesario y continuo, cuando este en realidad, en todo caso, procede por saltos, por botes o, como dirían los biólogos, por mutación y que no sigue una dirección única ${ }^{34}$. Como ejemplo paradigmático de los distintos grados de evolución de una civilización expone Braudel el caso de África: «Para un estudio de las civilizaciones, África Negra se presenta como un caso privilegiado... África negra tiene la inmensa ventaja de presentarse como un mundo cultural en plena evolución. Ofrece a nuestra observación todas las formas, desde las formas más arcaicas hasta las formas urbanas más progresivas, y todos los estadios de la «aculturación» ${ }^{35}$.

$\mathrm{Y}$ es que «las civilizaciones, por lo menos al principio de su destino, han sido todas ellas 'culturas' en el sentido dado a este término por los etnólogos, e incluso culturas primitivas. Después han permanecido ence-

\footnotetext{
${ }^{33}$ Op. cit., p. 97 y s.

${ }^{34}$ C. Lévi-Strauss, Raza e historia, Madrid, Cátedra, 1996 (París, 1952), pp. 23 y s.

${ }^{35} \mathrm{~F}$. Braudel, Las civilizaciones actuales, op. cit., p. 131.
} 
rradas, por más o menos tiempo y más o menos completamente, en un primer engranaje que es siempre de tipo religioso y mágico» ${ }^{36}$. Esta primera forma de civilización, transmitida oralmente durante siglos y siglos, constituiría el folklore, «la civilización tradicional», cuyas innumerables realidades vendrían de la prehistoria y estarían vivas todavía en el siglo $\mathrm{XX}$ : si se la quiere reconocer, habría que dejar a un lado, en las civilizaciones modernas, todo lo que es aristocrático, todo lo que es obra de los especialistas de un trabajo intelectual, todo lo que ha sido enseñado por los educadores profesionales, todo lo que ha sido dado a conocer en letra escrita o impresa. Lo que queda (las maneras de vivir, de pensar, de hablar y de actuar) tendría un carácter prodigiosamente vetusto. Este stock de tradiciones arcaicas se habría conservado más en unas civilizaciones que en otras. En Francia, y probablemente en todo el Occidente, esta tradición oral anterior a la escritura acabaría de desaparecer, en el siglo pasado, con los ferrocarriles, con la multiplicación de los medios de comunicación y de los desplazamientos y con la eficacia de la enseñanza primaria.

Esta desaparición progresiva es la clave de los conflictos internos de una civilización de los cuales ésta es más o menos consciente. «Una civilización aristocrática, burguesa, urbana, técnica, racionalista, lleva a cabo una lucha sin fin contra la civilización tradicional, supervivencia de su antigua cultura y tan difícil de extirpar como la grama. Puede vencerla poco a poco, pero nunca completamente ${ }^{37}$. Las razones serían múltiples: en primer lugar, porque nunca sería por sí misma perfectamente urbana, aristocrática, burguesa y, sobre todo, racionalista. Además, el pasado multiforme que se defiende frente a ella, fuera de ella, conservaría también un lugar secreto el interior mismo de los espíritus llamados evolucionados, porque harían falta siglos para que este pasado sea definitivamente eliminado de los espíritus.

Pero el aspecto más rechazable del pensamiento braudeliano es, sin duda, la gran cantidad de juicios de valor que transmite a la hora de poner en tela de juicio a la civilización tradicional respecto a la civilización moderna. Braudel se convierte en un apóstol de la modernización, en de-

\footnotetext{
${ }^{36}$ Op. cit., p. 45.

${ }^{37}$ Ibid.
}

«CUADERNOS DE ESTUDIOS GALLEGOS», Tomo L, Fascículo 116, Santiago 2003. 
trimento de la civilización tradicional, que debe ser rechazada de plano del mismo modo que esos países que se encuentran en la actualidad deprimidos, económicamente hablando, esas «civilizaciones que se han mantenido en la felicidad, en el paraíso y la pesadilla de su infancia, y que se han visto obligadas a abandonarlos para incorporarse al universo de la ciencia moderna $\iota^{38}$. El conflicto cobra proporciones gigantescas, porque el pasado tradicional es todavía muy poderoso.

Veamos algunos ejemplos, para poder comprender mejor la intención de Braudel. Comenzamos por el caso del Islam. A juicio de Braudel, «pase lo que pase, el Islam debe modernizarse, adoptar un buen número de técnicas de Occidente, que se han convertido hoy día en las bases de la vida mundial: el porvenir dependerá de la aceptación o del rechazo de esta civilización mundial $»^{39}$. La tradición, poderosa, quiere rechazarla. Sin embargo, el Islam habría aceptado parte de este mundo moderno que le asalta, y podría, por tanto, asimilar más aún. En el pasado, tampoco el cristianismo se habría adaptado fácilmente, pero finalmente, no habría perdido nada de su originalidad al hacer estas «concesiones necesarias». De hecho, una serie de reformas habrían barrido gran parte de los pretendidos tabúes de la civilización musulmana. En este sentido, el ejemplo más significativo que encuentra Braudel es el de la emancipación de la mujer, que estaría camino de afirmarse y más lentamente de realizarse. La desaparición de la poligamia, las limitaciones impuestas al repudio unilateral del marido, la supresión del velo, el acceso a la Universidad y a la cultura, a los empleos, al derecho de votar serían los siguientes pasos a dar. «Son testimonio de que el reformismo no es una causa perdida por anticipado, sino que exige abogados y promotores decididos. La lucha que se inicia será múltiple» ${ }^{40}$.

Pero Braudel no se limita a aconsejar una modernización a la occidental del Islam, sino que además se permite el lujo de mostrar el camino, el método más adecuado, situándose una vez más a la altura de los sabios consejeros de los príncipes del pasado. «El ideal es llevar a cabo las reformas por turnos y, en cada caso, escoger lo fundamental. Pero la política

\footnotetext{
${ }^{38} \mathrm{Ibid}$.

${ }^{39}$ Op. cit., p. 91.

${ }^{40}$ Op. cit, p. 92.
}

«CUADERNOS DE ESTUDIOS GALLEGOS», Tomo L, Fascículo 116, Santiago 2003. 
no es una especulación cartesiana. El progreso económico exigiría, por sí solo, en Islam y fuera de él, una política de preferencia, por no decir exclusiva. Pero el mundo en el que hay que vivir obliga muchas veces a enfrentarse con las dificultades, tanto las viejas como las nuevas, en el orden en el que se presentan $\rangle^{41}$.

Por lo que a África se refiere, «las culturas y las religiones primitivas representan un obstáculo: todo el pasado tradicional está frenando el empuje general, y complicando o, por lo menos, retrasando las adaptaciones necesarias ${ }^{42}$, sobre todo teniendo en cuenta que la mayor parte de las poblaciones de África negra (sobre todo en los medios rurales, que constituyen la enorme mayoría de sus territorios) estaría aún encerrada en culturas y religiones primitivas, en las que se basa todo el orden social.

En el caso del Extremo Oriente, su extraordinaria fidelidad para consigo mismo, su inmovilismo, se debería fundamentalmente a razones internas. Explican, en parte, su retraso, que, por lo demás, sería muy relativo. «En realidad, el Extremo Oriente nunca ha retrocedido; durante siglos y siglos, ha permanecido donde estaba, mientras que el resto del mundo iba progresando, distanciándose de él cada día más» ${ }^{43}$. Las razones del inmovilismo cultural oriental tendrían unos orígenes muy lejanos. «Todo se decidió, sin duda, con anterioridad a la historia, en el mismo amanecer de las primeras civilizaciones. Las civilizaciones del Extremo Oriente se presentan como conjuntos que hubieran alcanzado, muy precozmente, una asombrosa madurez, pero en un marco tal que ha hecho inmutables algunas de sus estructuras fundamentales. De este hecho han sacado unas esenciales unidad y cohesión. Pero también una extremada dificultad en transformarse por sí mismas, en querer y en poder evolucionar, como si se hubieran negado sistemáticamente al cambio y al progreso ${ }^{44}$. Además de unas formas religiosas antiguas y vivas, habría que añadir unas estructuras sociales muy antiguas: el sistema indio de las castas, la jerarquía familiar y social china. Se trataría en ambos casos de una perennidad religiosa, coexistente con una perennidad social y estrechamente relacionadas con ella. «Este rango es característico de todas las culturas primitivas, en

\footnotetext{
${ }^{41}$ Ibid.

${ }^{42}$ Op. cit., p. 132.

${ }^{43} \mathrm{Op}$. cit., p. 157.

${ }^{44}$ Ibid.
}

«CUADERNOS DE ESTUDIOS GALLEGOS», Tomo L, Fascículo 116, Santiago 2003. 
las que todas las formas de vida y pensamiento están total y directamente ajustadas a lo sobrenatural. Pero esto resulta más desconcertante $-\mathrm{y}$ también más notable- en civilizaciones tan importantes, tan desarrolladas en todos los campos, como China y la India» ${ }^{45}$.

No deja de ser sorprendente que un autor tan abierto a las lecciones del resto de las ciencias humanas, no se haya dejado influir por los desarrollos de la antropología de su época, que, al menos en parte, ya se había liberado de este tipo de juicios de valor al abandonar la asociación de estas poblaciones con el animismo, la magia o el pensamiento prelógico. A la inversa que en Occidente, que separaría claramente lo humano de lo divino, el Extremo Oriente desconocería esta diferenciación: «Lo religioso se confunde con todas las formas de la vida humana: el Estado es religión, la filosofía es religión, la moral es religión, las relaciones sociales son religión. Todas estas formas participan plenamente de lo sagrado. Y probablemente toman de él su tendencia a la inmutabilidad y a la perpetuidad» ${ }^{46}$.

Sin embargo, por muy lenta que haya sido la evolución de esta enorme realidad, es indudable que ha existido. «Como todas las civilizaciones, la civilización china acumula sus experiencias, va haciendo una selección, renovada continuamente entre sus propias riquezas y tendencias; por último, contrariamente a las apariencias, no está cerrada al mundo exterior. Aires extranjeros llegan hasta ella imponiéndole su presencia» ${ }^{47}$. Y más adelante, nos dice: «después de una larga y penosa experiencia, China se encuentra en uno de esos escasos momentos en que una civilización se renueva, después de haber roto consigo misma y de haber sacrificado algunas de sus estructuras que hasta ahora le eran imprescindibles. Para China, la crisis es tanto más extraordinaria cuanto que las estructuras puestas en tela de juicio databan de varios miles de siglos. Pero su destrucción no será, porque no puede serlo, total, y, en su trabajo de reconstrucción, China permanecerá fiel a unas formas de pensamiento y de sensibilidad que le son propias. Sin duda serán necesarios varios decenios para que se abra paso definitivamente la nueva civilización china, hoy día en período de gestación $»^{48}$.

\footnotetext{
${ }^{45}$ Op. cit., p. 158.

${ }^{46} \mathrm{Ibid}$.

${ }^{47}$ Op. cit., p. 160.

${ }^{48}$ Op. cit., p. 184.
} 
Pero el caso que más solivianta a Braudel es el de la India. «Es un hecho establecido que el hinduismo constituye el obstáculo principal y la dificultad fundamental para cualquier tipo de evolución o de modernización serias» ${ }^{49}$. La civilización hindú seguiría manteniendo a la masa de la población dentro de sus redes múltiples y rígidas. Para liberarse de las castas y tener acceso a la revolución social constituida por la vida moderna, el hindú tendría que penetrar necesariamente en un universo que no es el suyo. El aspecto más nocivo del hinduismo sería el sistema de las castas que encierra a la población en compartimentos múltiples y estancos. Sin embargo, desde los años cincuenta o sesenta, «la India es consciente del obstáculo que supone para ella su tradición cultural $)^{50}$. Esta toma de conciencia se habría operado en los tiempos de Gandhi. El problema es que Gandhi se habría apoyado en todas las tradiciones espirituales de la India para impulsarla hacia el progreso tal como él lo concebía, y hacia el orgullo nacional, pero esta tradición, a la que intentaba dar nueva vida, suponía, en muchos puntos, a juicio de Braudel, la prohibición para la India de alcanzar un cierto modernismo: «Gandhi se veía fatalmente alejado de toda revolución social por sus mismos principios. La revolución para él tenía que hacerse en los corazones. No se trataba de trastocar el orden existente, sino de conseguir de los hombres, fuera cual fuera su riqueza y su influencia, que se dediquen al servicio de sus semejantes, que acepten, según las mismas palabras de Gandhi, 'penetrarse del arte y de la belleza, de la abnegación y de la pobreza voluntarias; consagrarse a estas actividades que son el fundamento de una nación hilando y tejiendo con sus manos...; suprimir de su corazón todo prejuicio de casta en todas sus formas, haciendo campaña para la abstinencia total de las bebidas y de las drogas..., y de manera general cultivar la pureza del ser. Estas son maneras de vivir a la escala del pobre', preferentemente en el cuadro tradicional de la vida rural $\aleph^{51}$. Era volver a un espíritu trasnochado de paternalismo, inconscientemente reaccionario que «equivalía evitar el enfrentarse con la ruptura de la India con ciertos aspectos de su pasado, indispensable si quería triunfar del subdesarrollo y de la miseria de las masas $\rangle^{52}$. Braudel se inclina por Nehru.

\footnotetext{
${ }^{49}$ Op. cit., p. 224.

${ }^{50}$ Op. cit., p. 225.

${ }^{51}$ Op. cit., p. 226.

${ }^{52}$ Ibid.
}

«CUADERNOS DE ESTUDIOS GALLEGOS», Tomo L, Fascículo 116, Santiago 2003. 


\section{UNIFORMIDAD Y DIVERSIDAD DE LAS CIVILIZACIONES}

Según Braudel, las civilizaciones se ven forzadas a repartirse los bienes, los instrumentos y ciertos prejuicios comunes. «Por todas partes, $l a$ civilización ofrece sus servicios, sus stocks, sus diferentes mercancías $\rangle^{53}$. Sin embargo, aunque ofrezca estas mercancías, no siempre las da. Braudel ve en este aspecto de la civilización un factor de desigualdad en el mundo, de diversidad. Es más, «si tuviéramos ante los ojos un mapa de la distribución de las grandes fábricas, de los altos hornos, de las centrales eléctricas y, en un futuro próximo, de las fábricas atómicas, o también un mapa del consumo en el mundo de los productos esenciales, no nos sería difícil constatar que esas riquezas y estos instrumentos se encuentran muy desigualmente repartidos entre las diferentes regiones de la tierra ${ }^{54}$. Hay, por una parte, los países industrializados y, por otra, los subdesarrollados. $L a$ civilización no está equitativamente repartida.

En suma, aunque efectivamente existe una inflación de la civilización, sería inoportuno, a juicio de Braudel, considerar que, más allá de su triunfo, «elimine a las diferentes civilizaciones, verdaderos personajes, siempre vigentes y dotados de larga vida. Son ellos quienes, a propósito del progreso, emprenden la carrera, cargan sobre sus espaldas el esfuerzo a realizar, le confieren -o no- un sentido ${ }^{55}$. Ninguna civilización habría dicho que no al conjunto de estos bienes nuevos; pero cada una de ellas le confiere un significado particular. Existe el contexto humano, social, político y hasta místico. En este sentido, «la herramienta es muy importante, pero el obrero también lo es, así como la obra y el interés que en ella se pone o no se pone. Habría que estar ciego para no sentir el peso de esta transformación masiva del mundo. Pero no se trata de una transformación omnipresente; y allí donde se realiza, lo hace de forma y con una amplitud y una resonancia humanas rara vez semejantes $)^{56}$.

Por tanto, el triunfo de la civilización en singular no supondría el desastre de los plurales. Plurales y singulares dialogan en Braudel, se agre-

\footnotetext{
${ }^{53}$ F. Braudel, «Aportación de la historia de las civilizaciones», en: La Historia y las ciencias sociales, op. cit., p. 191.

${ }^{54} \mathrm{Ibid}$.

${ }^{55}$ Ibid.

${ }^{56}$ Op. cit., p. 192.
}

«CUADERNOS DE ESTUDIOS GALLEGOS», Tomo L, Fascículo 116, Santiago 2003. 
gan y también se distinguen. El problema, el gran problema, a nuestro entender, es que no queda lo suficientemente claro cómo se pasa de la civilización a las civilizaciones, cuál es el límite que las separa, en qué medida las diferencias no ponen en peligro la síntesis que supone en Braudel el concepto de civilización. Frente a la imagen tradicional del pasado histórico diverso y la contemporaneidad invadida de semejanzas, F. Braudel asegura que ya ocurría en el pasado que la unidad y la heterogeneidad cohabitaran. Reconoce que la diversidad del mundo de ayer obedecía a la inmensidad y a la dificultad de las distancias: montañas, desiertos, extensiones oceánicas y fajas de bosques constituían barreras reales. En este universo de compartimentos estancos, la civilización suponía forzosamente diversidad. Sin embargo, «si el historiador que se vuelve hacia esas edades caducadas extiende su mirada al mundo entero, percibe también, a miles de leguas de distancia, semejanzas asombrosas, ritmos muy análogos $\rangle^{57}$.

¿Es la uniformización técnica la causa, el gran artífice de la uniformidad? Braudel lo pone en duda. La causa estaría en el hombre braudeliano: «El hombre, en realidad, sigue siendo prisionero de un límite del que no es capaz de evadirse. Este límite es sensiblemente el mismo de un extremo a otro de la tierra; este límite es el que marca con un sello uniforme todas las experiencias humanas, cualquiera que sea la época considerada ${ }^{58}$. Así, por ejemplo, en la Edad Media, e incluso en el siglo XVI, la mediocridad de las técnicas, de las herramientas y de las máquinas, así como la escasez de los animales domésticos, habrían impuesto que toda actividad se redujera al hombre mismo, a sus fuerzas, a su trabajo; ahora bien, también el hombre escasearía, sería frágil, de vida endeble y corta. Todas las actividades, todas las civilizaciones se extenderían, de este modo, en un campo reducido de posibilidades. «Estas constricciones envuelven toda aventura, la restringen de antemano, le confieren en profundidad un aire de parentesco a través del espacio y del tiempo, ya que éste tardó en desplazar los lindes $)^{59}$. ¿Cuál es la novedad del siglo XX? Por una vez, en Braudel una discontinuidad, una revolución: «la revolución, la conmoción esencial del tiempo presente, consiste precisamente en el estallido

${ }^{57}$ Op. cit., p. 193.

${ }^{58}$ Ibid.

${ }^{59}$ Op. cit., p. 193 y s.

«CUADERNOS DE ESTUDIOS GALLEGOS», Tomo L, Fascículo 116, Santiago 2003. 
de esas 'envolturas' antiguas, de esas múltiples coacciones. Nada escapa a esta conmoción. Es la nueva civilización que pone a prueba a todas las civilizaciones ${ }^{60}$.

\subsection{La civilización industrial}

En la era contemporánea, una técnica industrial, inventada en Occidente, es exportada a través de todo el mundo. Es posible que se llegue, al imponer por todas partes un aspecto común -edificios de hormigón, de cristal y de acero, aeropuertos, líneas de ferrocarril, y puede que esta técnica industrial llegue a unificar el mundo. Todo esto es evidente. Sin embargo, Braudel está convencido de que «la 'civilización industrial', exportada por Occidente, es sólo uno de los caracteres de la civilización occidental. Al adaptarse a ella, el mundo está lejos de aceptar el conjunto de esta civilización ${ }^{61}$.

La propia historia le sirve a Braudel de base a sus afirmaciones, ya que, en su opinión, el pasado de las civilizaciones se reduce a la historia de las continuas transferencias entre unas, a lo largo de los siglos, sin que por ello hayan perdido ni sus particularidades ni su originalidad. Admite, sin embargo, que, «por primera vez, un aspecto decisivo de una civilización particular aparece como susceptible de ser asimilado por todas las civilizaciones del mundo y también que la rapidez de las comunicaciones modernas favorece su rápida y eficaz difusión $\rangle^{62}$. Cada una de estas civilizaciones ha sido, es, o será conmovida en sus estructuras profundas. Esta conmoción no habría de suscitar por todas partes las mismas formas de aceptación o de repulsa. De manera que, suponiendo que todas las civilizaciones del mundo lograsen en un plazo más o menos corto uniformar sus técnicas más usuales y a través de éstas algunos de sus modos de vida, «aun así, y por mucho tiempo todavía, nos encontraremos, en fin de cuentas, con una serie de civilizaciones muy diferenciadas. Durante mucho tiempo todavía, la palabra 'civilización' conservará un singular y un plural. Y el historiador no titubea en afirmar esto categóricamente» ${ }^{63}$.

\footnotetext{
${ }^{60}$ Op. cit., p. 194.

${ }^{61} \mathrm{~F}$. Braudel, Las civilizaciones actuales, op. cit., p. 16.

${ }^{62}$ Ibid.

${ }^{63} \mathrm{Ibid}$.
} 
Si se piensa, por ejemplo, en las naciones de Europa, se podría dudar del poder del maquinismo para unificar y dar uniformidad al universo. Al ser partícipes de una misma civilización de conjunto, la del Occidente cristiano y humanista; al haber sido lanzadas casi al mismo tiempo, hace ya más de un siglo, en la misma aventura de la industrialización y dotadas de la misma técnica, de la misma ciencia, de instituciones análogas, de todas las formas sociales del maquinismo, estas civilizaciones europeas tendrían que haber perdido, según nos dice Braudel, hace tiempo, sus fuertes particularidades que permiten distinguir una civilización francesa, otra alemana, inglesa, mediterránea... «Por el contrario, un francés no tiene más que atravesar la Mancha, un inglés llegar al continente, un alemán ir a Italia, para convencerse, sin dificultad, de que maquinismo no supone forzosamente uniformidad» ${ }^{64}$. La técnica, incapaz de destruir los particularismos regionales, «no puede aspirar a anular las poderosas personalidades que constituyen las grandes civilizaciones, basadas en religiones, filosofías, valores humanos y morales totalmente diferentes ${ }^{65}$.

\subsection{Las civilizaciones nacionales}

La cuestión a la que nos acabamos de referir tiende a la uniformidad de la civilización. Ahora, trataremos el problema de las civilizaciones nacionales, es decir, la perseverancia de la diversidad, en particular en el interior de una misma civilización. Ejemplo clásico de conjunción de una civilización común y unas civilizaciones nacionales diferenciadas lo constituyen, para Braudel, la civilización europea y sus civilizaciones particulares. «Hemos descrito una Europa unitaria, comprometida en un mismo destino de conjunto por la religión, el pensamiento racionalista, la evolución de la ciencia y de la técnica, la búsqueda de la revolución y de la justicia social, y de las realizaciones imperiales. Pero, en todo momento, es fácil sobrepasar esta 'armonía' de conjunto y topar con las diversidades nacionales subyacentes. Estas abundan y son poderosas y necesarias. Pero también existen diferencias entre Bretaña y Alsacia, el Mediodía y el Norte de Francia; entre el Mezzogiorno y el Piamonte; entre Baviera y Prusia; entre Escocia e Inglaterra; entre los Flamencos y los Valones;

\footnotetext{
${ }^{64}$ Op. cit., p. 102.

${ }^{65} \mathrm{Ibid}$.
} 
entre Cataluña, Castilla y Andalucía. Y, sin embargo, no dan pie a ninguna argumentación que permita negar las unidades nacionales» ${ }^{66}$.

No obstante, estas últimas tampoco son la negación de la realidad de Europa. Cada Estado ha tendido siempre a formar un mundo cultural en sí. El problema para Braudel consistiría en que se habría «considerado desde demasiado cerca las piezas de un mosaico que, visto desde arriba, revela los claros dibujos de conjunto. ¿Por qué habría que elegir, de una vez para siempre, entre el conjunto y el detalle? Las dos verdades no se excluyen». Bonita metáfora, pero descarada incapacidad teórica para explicar coherentemente la diversidad europea, nos da la impresión.

¿Cuáles son los puntos de contacto? En primer lugar coloca Braudel las unidades brillantes: el arte y el espíritu. «Entendemos por unidades brillantes los puntos de unión y de contacto que dan a la civilización, en el plano más elevado de la cultura, del gusto y del espíritu, un aspecto fraternal, casi uniforme, como si estuviera invadida por una única y misma luz». Considerado en su conjunto, el espacio europeo formaría un área cultural bastante coherente y que, desde hace mucho, se habría afirmado como tal frente al mundo: El arte, la filosofía, la ciencia objetiva, las ciencias humanas, etc. son ejemplo de esta unidad. La literatura representa la unidad más imperfecta. Más que una literatura europea se debe hablar de literaturas nacionales entre las cuales existen numerosísimos puntos de contacto, pero también grandes discrepancias: «En este terreno, la unidad es mucho más imperfecta (sin duda, para mayor felicidad de todos) en la medida en que la literatura -ensayo, novela, teatro- se apoya en lo que las civilizaciones tienen de más original: el idioma, la vida cotidiana, la manera de reaccionar ante el placer, el dolor, la idea del amor, de la muerte y de la guerra; su manera de distraerse, de beber, de comer, de trabajar, de creer... A través de la literatura, las naciones vuelven a ser personajes, individuos a los que se puede analizar, hasta psicoanalizar, gracias a este testimonio esencial $\rangle^{67}$. Además, desde hace mucho tiempo, Europa estaría inserta en las redes de una economía unitaria; en todas las épocas, su vida material habría girado en torno de diferentes centros autoritarios y privilegiados. «Europa constituyó en seguida un

\footnotetext{
${ }^{66}$ Op. cit., p. 337

${ }^{67}$ Sobre este tema, cf. Las civilizaciones actuales, op. cit., pp. 338-342.
} 
espacio material coherente, penetrado por una ágil economía monetaria, animado por una activa circulación $\rangle^{68}$. Aunque esto no quiere decir que toda la vida europea avance a un mismo ritmo y se alinee al mismo nivel.

La política, por el contrario, se muestra reticente a la unidad. «Tiene sus motivos para ello, motivos válidos, menos válidos y también falsos... La realidad es que toda Europa está desde hace mucho integrada en un mismo juego político, al margen del cual no ha podido permanecer ningún Estado so pena de perderse» ${ }^{69}$. Pero este juego no tiende a la unidad política; por el contrario, divide a Europa en grupos cuyos componentes han variado con frecuencia, siendo regla dominante el impedir que una homogeneidad imponga su ley a toda la familia de Estados. En todo caso, es evidente, para Braudel, que nos encontramos en presencia de «una continuidad de civilización. De hecho, de una doble o triple continuidad, ósmosis entre el Cercano Oriente y Grecia, de la misma manera que ha habido transferencias de Grecia a Roma. Y, por último, desde el Occidente romanizado al Occidente medieval no se produjo, ni mucho menos, una ruptura catastrófica» ${ }^{70}$.

En el caso del Islam, ¿existe aún, dentro de la inmensa desintegración de las nacionalidades y de las rivalidades políticas, una civilización musulmana, que todavía pueda ser reconocida? ¿Existe todavía una civilización musulmana? Las divisiones políticas del Islam parecen excluir, por mucho tiempo todavía, la consecución de los sueños de los panislamistas. «No obstante, el panislamismo existe lo mismo hoy que ayer, como hecho y realidad de civilización $\aleph^{71}$. En la vida cotidiana se podrían encontrar síntomas de esta civilización, de un extremo a otro de su espacio. En una similitud de creencias, de costumbres, de relaciones familiares, de gustos, de placeres, de juegos, de comportamientos y hasta de cocina...

El problema puede complicarse aún más porque cada civilización nacional puede dividirse en una serie de civilizaciones regionales o locales que difícilmente pueden hacer brillar sus colores sin negar los de su civilización nacional. Para el estudio de esta cuestión vamos a seguir los análisis braudelianos respecto de la civilización francesa en La identidad de

\footnotetext{
${ }^{68}$ Op. cit., p. 343

${ }^{69}$ Op. cit., p. 349 y s.

${ }^{70}$ Op. cit., p. 365.

${ }^{71}$ Op. cit., p. 100.
}

«CUADERNOS DE ESTUDIOS GALLEGOS», Tomo L, Fascículo 116, Santiago 2003. 
Francia. «El actual espacio francés, el 'hexágono', no es la única medida a la que uno deba referirse: por debajo de ella hay inframedidas, hay regiones, provincias, 'tierras', terruños que durante mucho tiempo conservaron y conservan aún una autonomía cierta; y por encima de ella está Europa y por encima de Europa está el mundo» ${ }^{72}$. Sin embargo, el diálogo con el mundo no implicaría que una nación quede expropiada o borre su propia historia. Se trataría de una mezcla, no de una fusión.

Por motivos desconocidos, Braudel decide prescindir de la palabra que durante toda su vida, a lo largo de su monumental obra, había privilegiado: civilización. Sin embargo, como enseguida comprobaremos, poco importan las palabras, sino el uso que se les da. Y podemos asegurar que identidad es simplemente un sinónimo de la civilización braudeliana, caracterizado por su misma ambigüedad, su carácter meramente descriptivo y su pretendido valor explicativo dentro del campo de la historia. «¿Qué debe entenderse por identidad de Francia?... En suma, un residuo, una amalgama, un conjunto de agregados, de mezclas; un proceso, una pugna contra sí misma destinada a perpetuarse. Si ese proceso se interrumpiera, todo se vendría abajo. Una nación sólo puede ser al precio de buscarse ella misma sin cesar, de transformarse en el sentido de su evolución lógica, de oponerse a lo demás sin desfallecimientos, de identificarse con lo mejor, con lo esencial de sí misma, y en consecuencia de reconocerse a la vista de imágenes propias, de contraseñas conocidas por los iniciados (ya sean estos una elite, ya sea la masa entera del país, lo que no siempre es el caso). Reconocerse en mil pruebas, creencias, discursos, coartadas, vasto inconsciente sin riberas, oscuras confluencias, ideologías, mitos, fantasías.... $\rangle^{73}$. Solamente desde una perspectiva irracional puede ser valorada esta definición como soporte de un discurso histórico.

Sin embargo, estas observaciones le permiten a Braudel preparar al lector para terminar aconsejándole que desconfíe de antemano de todo el lenguaje que sea demasiado simple: sería vano reducir Francia a un discurso, a una ecuación, a una fórmula, a una imagen, a un mito. «No creo, lo repito, en una 'esencia' de Francia (ni por lo demás de España); no

${ }^{72}$ F. Braudel, La identidad de Francia, Barcelona, Editorial Gedisa, 1993 (París, 1986), I, p. 18.

${ }^{73}$ Op. cit., I, p. 21.

«CUADERNOS DE ESTUDIOS GALLEGOS», Tomo L, Fascículo 116, Santiago 2003. 
creo en ninguna fórmula simple. Tampoco creo en el valor de la palabra y del concepto de decadencia. Me propongo tan sólo llevar a cabo una indagación razonable, ajena a todo apriorismo, y utilizar sucesivamente varios observatorios para procurar, partiendo de ellos, comprender cómo la larga historia de Francia se organiza en profundidad, se abandona a sus propias corrientes y a las corrientes del mundo».

Ante una observación preliminar la unidad de Francia se borra. Cada ciudad, cada región, cada provincia tendría sus netas originalidades. Y no se trataría tan sólo de las particularidades que señalan los paisajes y las marcas que el hombre les agregó, sino que «se trata también de una cultura vivida», «una manera de vivir y de morir, un conjunto de reglas que definen las relaciones humanas fundamentales entre padres e hijos, entre hombres y mujeres, entre amigos y vecinos».

En el plano estrictamente cultural, si en el piso más elevado hay una «civilización» francesa una, elitista, que se consideraría brillo, esplendor, superestructura, dominación, no por eso dejaría de haber en Francia y enfrentadas desde hace siglos por lo menos dos grandes civilizaciones subyacentes, cada una de ellas con su reino lingüístico: la civilización del oül que resultó victoriosa y la civilización del $o c$ a la que el destino reservó la situación en general de una casi colonia. El Norte la aplasta con su éxito material. «Generalmente, lo que ocurre en el Norte no sucederá de la misma manera en el Sur y viceversa: la civilización (modo de nacer, de vivir, de amar, de casarse, de pensar, de creer, de reír, de alimentarse, de vestirse, de construir casas, de cultivar campos, de conducirse los unos respecto de los otros) no es casi nunca la misma civilización del sí nórdico y del sí meridional, del oïl y del oc. Hubo, hay todavía y habrá siempre en el Sur 'otra' Francia».

¿Es todo esto serio? ¿Es acaso válido, para el desarrollo de un discurso histórico coherente, que abandone el uso de conceptos cargados de irracionalidad y de juicios de valor, el uso de un concepto meramente descriptivo, que se olvida de mostrarnos, en este caso concreto, las relaciones («no hay nada claro sino las relaciones», como aseguraba Wittgenstein), las vías que engarzan esta tipología diferenciada de civilizaciones, que flota, en definitiva, para no hundirse en su propia ambigüedad? Volveremos sobre ello más adelante. 


\section{3. ¿Constituye el marxismo una auténtica civilización?}

El problema que se plantea Braudel es saber en qué medida la adopción de un sistema marxista podría uniformizar de alguna manera esta diversidad evidente de las civilizaciones. En algunos casos, como por ejemplo el Islam, el asunto se complica ante la posibilidad de que se lance por ese camino, capaz de destruir uno de sus gérmenes de cohesión, es decir, la religión. Sin embargo, «el marxismo no es, por sí solo, una civilización de sustitución; es una orientación social, un humanismo voluntario, una racionalización. Si algún día se aplicara en el Islam, daría lugar, sin duda, a una coexistencia, a una diferenciación, como en los países soviéticos entre civilización rusa y marxismo, como en China entre civilización china y marxismo. Aunque las ha influido y orientado poderosamente, el marxismo no ha terminado con ninguna de estas dos civilizaciones y su programa no consiste en esto ${ }^{74}$.

Por lo que respecta a Europa y Rusia, a principios del siglo XX se encontrarían inmersas en la misma civilización. «Y en el plano de las realidades de la civilización, cuarenta años significan muy poco. A pesar de la fantástica conmoción de las estructuras sociales, la Rusia de 1965 sigue perteneciendo a la misma civilización que la Rusia de 1917, es decir, a la nuestra ${ }^{75}$. De modo que «en el futuro, podrá hablarse de una 'civilización soviética', pero no de momento ${ }^{76}$. Por estas razones, Braudel ha evitado el empleo de esta expresión. El comunismo constituiría una puesta en orden de una civilización que le es anterior, que soportaría un choque, pero deformaría sus cuadros.

Esta discusión remite a la definición braudeliana de civilización: la civilización es el más amplio de los movimientos de la historia. No se puede confundir ni con las instituciones políticas, ni con la ideología, ni con las religiones o los órdenes sociales, todos ellos realidades que implica la misma civilización. Resulta poco razonable contraponer, para Braudel, por ejemplo, «una civilización soviética» a una «civilización occidental» porque equivaldría a equivocarse sobre su concepto de civilización.

\footnotetext{
${ }^{74} \mathrm{Ibid}$.

${ }^{75}$ Op. cit., I, p. 483.

${ }^{76}$ Op. cit., I, p. 496.
}

«CUADERNOS DE ESTUDIOS GALLEGOS», Tomo L, Fascículo 116, Santiago 2003. 


\section{EL TRIPLE MECANISMO DE LA DEFINICIÓN BRAUDELIANA DE CIVILIZACIÓN: EL ÁREA CULTURAL, EL PRÉSTAMO Y LA REPULSA}

A estas alturas de nuestro estudio hemos puesto de relieve algunos de los vínculos entre los conceptos de civilización y de longue durée en la obra de Fernand Braudel. Sin embargo, en este epígrafe trataremos de hallar las claves reales de este concepto, ya que lo que ahora se plantea es directamente lo que él entiende por «civilización». En este sentido Braudel no repara en reconocer sus deudas: la definición que propone Braudel se encuentra «bien en la enseñanza de este o aquel antropólogo, bien en determinado informe de $\mathrm{M}$. Mauss, de quien la he tomado hace poco sin haber tenido que arrepentirme ${ }^{77}$. La definición que Braudel ha tomado prestada apunta a un triple mecanismo: el área cultural, con sus fronteras; el préstamo; la repulsa. De todo ello trataremos a continuación.

\subsection{El área cultural}

La adopción del concepto de área cultural tiene una importancia enorme, lógicamente, al hacer de él el primer pilar de su definición de civilización. Aunque ha nacido a partir de las investigaciones antropológicas, «el área cultural pertenece... al dominio de la geografía en mucho mayor grado de lo que piensan los antropólogos» ${ }^{78}$. Para los antropólogos, un área cultural es un espacio en el interior del cual predomina la asociación de ciertos rasgos culturales.

¿Qué relación tiene exactamente un área cultural con una civilización? «Una civilización es, en primer lugar, un espacio, un 'área cultural', como dicen los antropólogos, un alojamiento. Imagínese en el interior de una localización, más o menos amplia pero nunca reducida, una masa muy diversa de 'bienes', de rasgos culturales: tanto la forma, el material o los tejados de las casas como un determinado arte de emplumar las flechas, un dialecto o un grupo de dialectos, unas aficiones culinarias particulares, una técnica peculiar, una manera de creer, una forma de amar, o tam-

${ }^{77}$ F. Braudel, «Aportación de la historia de las civilizaciones», en: La Historia y las ciencias sociales, op. cit., p. 174.

${ }^{78}$ Ibid.

«CUADERNOS DE ESTUDIOS GALLEGOS», Tomo L, Fascículo 116, Santiago 2003. 
bién la brújula, el papel, la prensa del impresor» ${ }^{79}$. O también, esta otra cita: «Así, por ejemplo, cuando se trata de pueblos primitivos, además del idioma, determinadas culturas de subsistencia, determinada ceremonia matrimonial, determinadas creencias, técnicas de alfarería, de flechas guarnecidas de plumas o de fabricación de tejidos... Estas áreas, distinguidas por los antropólogos, definidas a partir de detalles precisos, son, por lo general, pequeñas. Sin embargo, determinadas áreas culturales se agrupan en conjuntos más amplios, según ciertos rasgos comunes al grupo y que, entonces, las diferencian de otros amplios conjuntos. Marcel Mauss creía que, en torno al inmenso océano Pacífico, las culturas primitivas formaban, a pesar de las sensibles diferencias existentes entre ellas y de la enormidad de los espacios interpuestos, un único y coherente con-

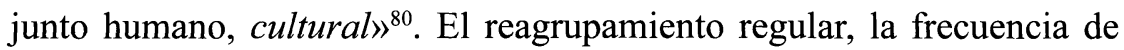
ciertos rasgos y la ubicuidad de éstos en un área precisa constituyen los primeros síntomas de una coherencia cultural. «Si a esta coherencia en el espacio se añade una permanencia en el tiempo, llamo civilización o cultura al conjunto, al 'total' del repertorio. Este total constituye la forma de la civilización así reconocida» ${ }^{81}$.

Por tanto, siguiendo el ejemplo de los antropólogos, Braudel ha aceptado, a propósito de civilizaciones evolucionadas y complejas, el concepto de áreas culturales. Lo que equivale a designar espacios susceptibles de ser desintegrados en una serie de distritos particulares. Para Braudel, esta posible desintegración continúa siendo fundamental en el caso de las grandes civilizaciones que generalmente se disocian en unidades restringidas. Así, la llamada civilización «occidental» está constituida tanto por la civilización de los Estados Unidos, la de América Latina, la de Rusia y la de Europa. Europa misma comprende una serie de civilizaciones, la polaca, la alemana, la italiana, la inglesa, la francesa, etc. Sin contar con que estas civilizaciones nacionales se dividen a su vez en «civilizaciones» todavía más pequeñas: Escocia, Irlanda, Cataluña, Sicilia, País Vasco, etc.. «No hay que olvidar que estas divisiones, estos mosaicos de piezas de diferente color, son prácticamente rasgos permanentes $\rangle^{82}$.

\footnotetext{
${ }^{79}$ Ibid.

${ }^{80}$ F. Braudel, Las civilizaciones actuales, op. cit., p. 25.

${ }^{81}$ Ibid.

${ }^{82}$ Ibid.
}

«CUADERNOS DE ESTUDIOS GALLEGOS», Tomo L, Fascículo 116, Santiago 2003. 
Este área, además, posee un centro, un «núcleo», unas fronteras y unos márgenes propios. En el margen se encuentran precisamente, con la máxima frecuencia, los rasgos, los fenómenos o las tensiones más características. A veces estas fronteras y el área que encierran son inmensas, de modo que un área reúne siempre varias sociedades o grupos sociales. «De ahí la necesidad de prestar atención, en la medida de lo posible, a la más pequeña unidad cultural. ¿Qué espacio exige, en una u otra parte?, ¿cuántos hombres, cuántos grupos sociales diferentes?, ¿cuál es su mínimo vital?» ${ }^{83}$.

\subsection{La difusión de los bienes culturales}

El segundo pilar sobre el que articula Braudel su definición de civilización es la difusión de los bienes culturales. «La irradiación, la exportación, no es una manifestación, entre tantas, de la vida de las civilizaciones. Aunque es evidente que sólo son civilizaciones vivas las capaces de exportar sus bienes a distancia, de irradiar. Sería inconcebible una civilización que no exportase con sus hombres sus maneras de pensar y de vivir» ${ }^{84}$. Braudel nos asegura que no hay ninguna sociedad, brillante o primitiva, que no sea afectada en todo su espesor por contagios e intrusiones culturales que, en realidad, no dejan nada fuera de sus dominios, ni los humildes detalles de la vida cotidiana, ni las cimas de la vida intelectual. Toda sociedad es por tanto cultura, sea que consideremos la planta baja, sea que miremos los pisos superiores de la vida. Y de modo paralelo, toda sociedad es civilización.

Los bienes culturales serían, en efecto, muy diversos, innumerables, materiales unos, inmateriales otros. Y su característica común es su constante desplazamiento, su difusión ininterrumpida: técnicas, vestidos, palabras saltando de una lengua a otra, artes de vivir que se copian, pensamientos sutiles, formas políticas y sociales, creencias, desasosiegos religiosos, deriva sin réplica de ese sistema incansable de irradiación. Todos estas transferencias demostrarían que no existen fronteras cerradas ni impermeables. La mayor parte de las transferencias culturales se

${ }^{83}$ F. Braudel, «Aportación de la historia de las civilizaciones», en: La historia y las ciencias sociales, op. cit., p. 175.

${ }^{84} \mathrm{~F}$. Braudel, El Mediterráneo y el mundo mediterráneo en la época de Felipe II, México, Fondo de Cultura Económica, 1966, $2^{\text {a }}$ ed., corregida y aumentada, (París, 1966), II, p. 150 .

«CUADERNOS DE ESTUDIOS GALLEGOS», Tomo L, Fascículo 116, Santiago 2003. 
llevaron a cabo sin que conozcamos los vehículos. Éstos son muy numerosos, unos más rápidos y otros lentos, y proceden en direcciones muy distintas, de modo que no siempre es posible localizarlos en esta inmensa «estación de mercancías» donde nada permanece en su sitio. «Es relativamente fácil poner las cosas en orden cuando se trata de obras de arte... Lo es también cuando se trata de bienes tangibles, como las palabras, sean del vocabulario o las de la geografia; en estos casos, el control es posible, aunque no siempre absolutamente seguro. Pero cuando se trata de ideas, de sentimientos, incluso de técnicas, toda clase de errores son posibles ${ }^{85}$.

Desconfiemos, por tanto, de quienes creen reconocer sin vacilar los equipajes o de quienes, reaccionando contra aquéllos, niegan en bloque todo empréstito de unas civilizaciones a otras, siendo así que todo se intercambia: hombres y pensamientos, artes de vivir, creencias y maneras de amar... Estos intercambios son muy antiguos: los bienes culturales viajarían desde la Prehistoria: «Semejantes difusiones son en realidad tan viejas como el mundo de la inventiva. Y como el mundo de los hombres siempre fue inventivo, los inventos desde siempre recorrieron el planeta: piénsese en el hierro y en el bronce durante la Prehistoria, en la seda tanto tiempo codiciada que llegaba a Bizancio en los tiempos de Justiniano, en la pólvora de cañón que salía de China o, más cerca de nosotros, en el arte de los mineros o en el arte de la imprenta que los obreros alemanes llevaron a partir del siglo XV a toda Europa y muy pronto fuera de Europa ${ }^{86}$. De modo que el mundo moderno no tendría el monopolio de estas difusiones. Éstas, a veces, van en grupo: así se propagan el arte románico, el arte gótico, el arte del Renacimiento, el Barroco...

De este modo, los desplazamientos son a veces masivos, aunque muy lentos. Así, por ejemplo, «las transformaciones de vestuario, en Francia, hacia 1340, ven así la sustitución, por la falda flotante de los cruzados, del jubón corto y ceñido de los hombres, completado por los calzones ajustados y las puntas alargadas de las polainas, novedades todas ellas procedentes de Cataluña junto con la perilla y el mostacho a la española del siglo XIV, pero salidas, en realidad, de mucho más lejos todavía, del Oriente que frecuentaban los catalanes... Sin embargo, la ropa femenina,

\footnotetext{
${ }^{85}$ Op. cit., p. 149.

${ }^{86}$ F. Braudel, La identidad de Francia, op. cit., III, p. 305.
} 
sobre todo el adorno de picos, proviene de la corte de los Lusignan de Chipre y, más allá, a través del espacio y el tiempo, de la China de los Tang (extinguida a principios del siglo X). Porque con la irradiación incansable de las culturas ocurre a veces como con la luz de las estrellas lejanas, que nos llega cuando esas estrellas hace siglos o milenios que están apagadas.... ${ }^{87}$. Verdad de ayer y de antaño: «los bienes culturales llegaban por aquel entonces con cuentagotas, retardados por la lentitud de los viajes ${ }^{88}$. Sin embargo, las cosas han cambiado, y «en la actualidad, la difusión de los bienes culturales se ha acelerado pavorosamente. Dentro de poco no quedará en todo el mundo un sólo sitio que no esté 'contaminado' por la civilización industrial, nacida en Europa ${ }^{89}$. Puede darse el caso de que esta difusión, en continua aceleración, haga saltar algún día las fronteras de las civilizaciones y esos límites, hasta entonces más o menos fijos, de la historia del mundo. Pero sea cual sea la avidez de las civilizaciones en pedir prestados los avances de la vida «moderna», no estarían preparadas para asimilarlo todo indistintamente. Por el contrario, se da el caso de que se obstinen en rehusar ciertos préstamos, bo que explicaría que consigan salvaguardar sus originalidades, amenazadas por todos los lados. De manera que «las civilizaciones están incorporando continuamente bienes culturales de las civilizaciones vecinas, aunque luego los sometan a un 'reajuste' a fin de asimilarlos. A primera vista, toda civilización puede ser comparada a una estación de mercancías que no cesa de recibir y de reexpedir cargamentos heterogéneos».

«Se ve, pues, hasta dónde llegaría mi confianza en la 'difusión'»" ${ }^{90}$. En este caso, Braudel tampoco es un autor original, y trata de recoger el análisis de Claude Lévi-Strauss, como el propio Braudel reconoce: «¿Acaso no fue él quien explicó, con ocasión de una polémica, que las civilizaciones constituían, a su modo de ver, otros tantos jugadores en torno a una enorme masa, que dependía también, en cierta manera, de la teoría general de juegos? Imagínese que los jugadores se ayuden mutuamente, se comuniquen sus cartas o sus intenciones: cuanto más en convivencia es-

${ }^{87}$ F. Braudel, Escritos sobre la historia, op. cit., p. 139.

${ }^{88}$ F. Braudel, Las civilizaciones actuales, op. cit., p. 26.

${ }^{89}$ F. Braudel, Escritos sobre la historia, op. cit., p. 139.

${ }^{90} \mathrm{~F}$. Braudel, «Aportación de la historia de las civilizaciones», en: La historia y las ciencias sociales, op. cit., p. 179. 
tén, más oportunidad tendrá uno de ellos de ganar» ${ }^{91}$. Occidente se habría beneficiado, de este modo, entre otras cosas, de su posición de encrucijada de innumerables corrientes culturales. A lo largo de los siglos, ha estado recibiendo, recogiendo lo que le llegaba de todas las direcciones, hasta de civilizaciones hoy difusas, antes de ser capaz a su vez de dar, de irradiar.

A este respecto, Braudel cree que Francia todavía guarda sus privilegios: en la complicada trama de las transferencias e intercambios culturales, continúa siendo una encrucijada de elección, una especie de necesidad del mundo. «Esta apertura en la encrucijada francesa constituye sin duda el rasgo dominante de nuestra civilización. Es aún el origen de nuestra importancia y de nuestra gloria. María Curie nació en Varsovia, en una pequeña casa de la ciudad vieja que la fidelidad polaca ha sabido reconstruir; Modigliani es originario de Livorno; Van Gogh, de Holanda; Picasso nos viene de España; Paul Valéry tenía antepasados genoveses» ${ }^{92}$.

En el amplio presente todavía en «devenir», se estaría realizando, pues, una enorme «difusión». Tal difusión no sólo hace más intrincadas a las articulaciones antiguas y apacibles de las civilizaciones las unas con relación a las otras; complica también el mecanismo de cada una de ellas con relación a sí misma. «Todavía llamamos a esta difusión, en nuestro orgullo de occidentales, irradiación de nuestra civilización sobre el resto del mundo. Apenas puede exceptuarse de esta irradiación, a decir de un experto, a los indígenas del centro de Nueva Guinea o a los del este del Himalaya. Pero esta difusión en cadena, si ha sido alentada por Occidente, con toda evidencia se le escapa de ahora en adelante $\rangle^{93}$. Esas revoluciones existirían hoy día al margen de nosotros. Son la ola que engrosa desmesuradamente a la civilización de base del mundo. El tiempo presente estaría constituido, ante todo, por esta inflación de la civilización y, al parecer, por la revancha, cuyo final no se vislumbra, del singular sobre el plural.

En realidad, tan sólo «parece ser. Porque -ya lo he dicho e insisto en ello- esta nueva coacción o esta nueva liberación -en todo caso, este nuevo manantial de conflictos y esta necesidad de adaptaciones-, aunque

\footnotetext{
${ }^{91} \mathrm{Ibid}$.

${ }^{92}$ Op. cit., p. 178

${ }^{93}$ Op. cit., p. 196 y s.
}

«CUADERNOS DE ESTUDIOS GALLEGOS», Tomo L, Fascículo 116, Santiago 2003. 
afectan al mundo entero provocan en él movimientos muy dispares. No cuesta trabajo imaginar las conmociones a que esta brusca irrupción de la técnica y de todas las aceleraciones que provoca pueden dar lugar en el juego interno de cada civilización, en el interior de sus propios límites, materiales o espirituales. Pero este mecanismo no es claro; varía con cada civilización, y cada civilización se encuentra colocada respecto a él, sin quererlo, en una posición particular, en virtud de realidades muy antiguas y resistentes, puesto que constituyen su misma estructura ${ }^{94}$. Cada pueblo construiría, de esta manera, diariamente su destino, su «actualidad», con el conflicto $-\mathrm{o}$ el acuerdo- entre actitudes antiguas y nuevas necesidades.

Un aspecto fundamental dentro del desarrollo del tema que estamos tratando es la importancia del factor técnico en los intercambios entre civilizaciones. En principio, conviene aclarar qué es lo que entiende Braudel por técnica. A este respecto, una vez más la ambigüedad es la norma: «todo es técnica: el esfuerzo violento, pero también el esfuerzo paciente y monótono de los hombres sobre el mundo exterior; esas fuertes mutaciones que nos apresuramos a llamar revoluciones (la pólvora de cañón, la navegación de altura, la imprenta, los molinos de agua y de viento, el primer maquinismo), pero también las lentas transformaciones introducidas en los procedimientos y en las herramientas y esos innumerables gestos, desprovistos, sin embargo, de importancia innovadora: el marinero que tiende las jarcias, el minero que caba su galería, el campesino detrás de su arado, el herrero en su yunque... Todos esos gestos que son fruto de un saber acumulado. 'Llamo técnica, decía Marcel Mauss, a un acto tradicional eficaz'; en suma, un acto que implica trabajo del hombre sobre el hombre, un aprendizaje emprendido, perpetuado desde el principio de los tiempos» ${ }^{95}$.

La técnica tendría en definitiva la propia amplitud de la historia y forzosamente su lentitud, sus ambigüedades; se explicaría a través de la historia y la explica a su vez, sin que esta correlación, en un sentido o en otro, satisfaga plenamente. En este campo ampliado hasta los límites de la historia, no hay una acción, sino acciones y retrocesos múltiples, y

${ }^{94}$ Op. cit., p. 197.

${ }^{95} \mathrm{~F}$. Braudel, Civilización material, economía y capitalismo. Siglos XV-XVIII, Madrid, 1984 (París, 1979), I, p. 286.

«CUADERNOS DE ESTUDIOS GALLEGOS», Tomo L, Fascículo 116, Santiago 2003. 
múltiples «engranajes». Desde luego, Braudel no cree que se trate de una historia lineal.

La historia general y la sociedad tienen su parte de responsabilidad en un debate en el que la técnica nunca aparece aislada. La sociedad es entendida aquí como una historia lenta, sorda, compleja; una memoria que repetiría obstinadamente soluciones ya conocidas y adquiridas, que evitaría la dificultad y el peligro de soñar con nuevas aspiraciones. De modo que toda invención que intenta introducirse debe esperar años o incluso siglos para incorporarse a la vida real. «Existe la inventio, y mucho más tarde la aplicación (usurpatio), de alcanzar la sociedad el grado necesario de receptividad. Así sucedió con la guadaña» ${ }^{96}$.

Lo que quiere decir, a juicio de Braudel, que la técnica es unas veces esa posibilidad que los hombres, por razones sobre todo económicas y sociales, pero también psicológicas, son incapaces de alcanzar y de utilizar a fondo, y otras ese techo contra el que tropiezan material y «técnicamente» sus esfuerzos. En este último caso, bastaría que el techo se rompiese un buen día para que esa ruptura se convirtiese en el punto de partida de una fuerte aceleración. En todo caso, el movimiento que derriba el obstáculo nunca es tan sólo el simple desarrollo interior de la técnica y de la ciencia mismas, al menos con anterioridad al siglo XIX. La sociedad, otra vez, tiene algo que decir.

Concretamente, la artillería, la imprenta y la navegación de altura son, según Braudel, las mayores revoluciones técnicas entre los siglos XV y XVIII. Ninguna de ellas se habría realizado rápidamente. Y sólo la última acabó por crear un desequilibrio, una "asimetría» del mundo. Generalmente, a la larga, todo acaba difundiéndose: los números arábigos, la pólvora de cañón, la brújula, el papel, el gusano de seda... Lo que realmente nos interesa en relación con nuestro estudio es que «ninguna innovación se mantiene al servicio de un grupo, de un Estado o de una civilización; para que así fuera, haría falta que los demás no la necesitasen. En su lugar de origen, las nuevas técnicas se imponen tan lentamente que el vecino tiene tiempo de asombrarse y de informarse $)^{97}$.

\footnotetext{
${ }^{96}$ Op. cit., I, p. 288.

${ }^{97}$ Op. cit., I, p. 333.
} 
De entre todas las revoluciones técnicas, Braudel destaca una, porque fue la única que participó de lleno en el desequilibrio de las civilizaciones entre los siglos XV y XVIII. Se trata de la conquista de alta mar, que confirió a Europa su supremacía universal. En esta ocasión, la técnica (la navegación de altura) creó una "asimetría» a escala mundial, un privilegio. La expansión de Europa por todos los mares del mundo le plantea, de hecho, a Braudel, un gran problema: ¿por qué, una vez demostrada la posibilidad de la navegación de altura, no participaron en ella todas las civilizaciones marítimas del mundo? Todas, en principio, podían tomar parte en la competición. Pero sólo Europa persistió en el empeño. El hecho es muy sorprendente ya que las civilizaciones marítimas se conocen desde siempre y, todas juntas, atraviesan el Viejo Mundo con una línea continua desde el Atlántico europeo hasta el océano Indico, Insulindia y los mares próximos a las costas del océano Pacífico.

La explicación de Braudel combina causas económicas y evoluciones mentales. A partir del siglo XIII, una tensión de «longue durée» habría conmovido la vida material europea y habría transformado toda la psicología del mundo occidental. Lo que otros historiadores han llamado sed de oro, o una sed del mundo, o una sed de especias, se habría visto acompañada, en el campo de la técnica, por una búsqueda constante de novedades y de aplicaciones utilitarias, es decir, al servicio del hombre, para aliviar su esfuerzo y conferirle una mayor eficacia. La acumulación de descubrimientos prácticos y reveladores de una voluntad consciente de dominar el mundo, el gran interés por todo lo que pudiera ser fuente de energía, habrían dado a Europa, mucho antes de su triunfo, su auténtica imagen y la promesa de su preeminencia.

Sin embargo, habiendo señalado los límites evidentes de la técnica, sobre todo en lo que se refiere a su estricta dependencia del consentimiento social para que se produzca su desarrollo, no es intención de Braudel subestimar su papel, que a su juicio es primordial. De hecho, todo acaba, antes o después, por depender de ella, de su intervención, que se ha hecho necesaria. «Mientras la vida cotidiana se mantiene por su propio impulso sin demasiada dificultad, en el marco de sus estructuras heredadas, mientras la sociedad se contenta con su rodaje, encontrándose a gusto en él, no hay motivación económica que incite al esfuerzo del cambio... Cuando las cosas dejan de funcionar, cuando la sociedad choca con el límite de lo posible, se impone recurrir a la técnica, se despierta el 
interés por las numerosas invenciones entre las que habrá que escoger la mejor, la que rompa los obstáculos, la que abra un horizonte diferente ${ }^{98}$. Además, todas las reactivaciones del crecimiento económico habrían tenido siempre un soporte técnico. En este sentido, la técnica sería el factor esencial, ya que es ella la que cambia el mundo.

\subsection{Los rechazos de influencias}

Una civilización se resiste, por lo general, a la incorporación de una aportación cultural que ponga en tela de juicio una de sus estructuras profundas. Esta resistencia a nuevas incorporaciones son relativamente escasas, pero llevan generalmente al corazón de una civilización. Como ya hemos indicado, Braudel cree que las civilizaciones están incorporando continuamente bienes culturales de las civilizaciones vecinas, aunque luego los sometan a un «reajuste» a fin de asimilarlos. A primera vista, toda civilización podría ser comparada a una estación de mercancías que no cesa de recibir y de reexpedir cargamentos heterogéneos.

Sin embargo, puede darse el caso de que una civilización rechace obstinadamente una determinada aportación exterior. Para Braudel no cabe duda de que son también «grandes civilizaciones las que se niegan a tomar nada prestado y las que se oponen con vehemencia a marchar al paso, las que seleccionan cuidadosamente lo que los poderosos de fuera les proponen y les impondrían no pocas veces si no tropezaran con la vigilancia del destinatario, o simplemente con incompatibilidades de humor y de gusto. Sólo los utopistas (algunos de ellos, en el siglo XVI, verdaderamente admirables, como Guillaume Postel, por ejemplo) sueñan con fundir las religiones, lo más personal, lo que más resistencia ofrece a todos los bienes, fuerzas y sistemas que integran cualquier civilización. Es posible mezclarlas parcialmente, desplazar de una a otra tal o cual idea, un dogma, un rito; pero de eso a confundirlas, hay una distancia inmensa, infranqueable ${ }^{99}$.

Marcel Mauss había insistido en que no existe una civilización digna de este nombre que no tenga repugnancias y repulsas que le sean propias. Pero, en cada caso, la repulsa aparece como la decisión con la que termi-

\footnotetext{
${ }^{98}$ Op. cit., I, p. 379.

${ }^{99} \mathrm{~F}$. Braudel, El Mediterráneo y el mundo mediterráneo en la época de Felipe II, op. cit., II, p. 151.
}

«CUADERNOS DE ESTUDIOS GALLEGOS», Tomo L, Fascículo 116, Santiago 2003. 
nan una larga serie de vacilaciones y, por lo tanto, tiene una importancia tanto mayor cuanto que ha sido meditada y decidida muy lentamente. Expone, reiteradamente además, Braudel los casos de la Reforma, la toma de Constantinopla y el marxismo como ejemplos paradigmáticos de rechazo cultural: «Consideremos, por ejemplo, el caso de la Reforma, división profunda, decisiva de Europa. Italia, España y Francia (ésta tras terribles vacilaciones) rechazan la Reforma, las Reformas... Y se produce una tragedia de una amplitud y una profundidad inmensas. Afecta a lo más hondo de las culturas europeas. Otro ejemplo: en 1453, Constantinopla se niega a ser salvada por los latinos, esos hermanastros a los que detesta hasta tal punto que prefiere el dominio turco. Y también en este caso se produce una tragedia». O también: «Si queremos construir todo en torno a los rechazos, no se puede negar que de ellos se trata en el caso dramático actual del marxismo militante. El mundo anglosajón lo rechaza, en profundidad. Francia, Italia y España no le son hostiles pero le oponen también resistencia. Resistencia que afecta no sólo a los niveles económicos, a las estructuras sociales, al pasado reciente y a sus contingencias, sino también a las culturas» ${ }^{100}$. Y esta otra cita: «Que la Cristiandad mediterránea -Italia, Francia, España- haya rechazado en el siglo XVI la Reforma, mientras que el Norte, donde va a desarrollarse el capitalismo, une la revuelta de Lutero a la de Calvino, supone una quiebra profunda en el seno de Europa, una quiebra que ya no puede desaparecer. La Reforma pone al creyente frente al mismo Dios, terrible, dramático frente a frente, mientras que la Iglesia católica es protección tutelar, intermediaria entre Dios y el fiel...» $\rangle^{101}$.

En el caso de la toma de Constantinopla, la civilización griega habría demostrado que no había muerto todavía, y la prueba de ello sería que se sentía capaz de «rechazos» no menos categóricos, y no menos dramáticos. «Moribunda, o por mejor decir, amenazada de muerte, en el siglo $\mathrm{XV}$, rehusó unirse a la Iglesia latina. El problema volvió a plantearse en el siglo XVI: nuevo rechazo, no menos enérgico... ¡Cuántas estúpidas veja-

${ }^{100}$ F. Braudel, «Aportación de la historia de las civilizaciones», en: La Historia y las ciencias sociales, p. 178. Y también, para los mismos ejemplos, El Mediterráneo y el mundo mediterráneo en la época de Felipe II, op. cit., II, pp. 152-158; Las civilizaciones actuales, op. cit., p. 38 y Escritos sobre la historia, op. cit., p. 139 y s.

${ }^{101}$ F. Braudel, Escritos sobre la historia, op. cit., p. 139 y s.

«CUADERNOS DE ESTUDIOS GALLEGOS», Tomo L, Fascículo 116, Santiago 2003. 
ciones habían tenido que soportar los obispos griegos! El clero católico de las posesiones venecianas había adoptado siempre hacia ellos una actitud despectiva; no había procurado sacarlos de su 'error' la mayor parte de las veces, más que por medio de la violencia, prohibiéndoles o imponiéndoles tal o cual rito, tratando de desterrar la lengua griega de las iglesias, etc. Era natural que los griegos prefirieran entregarse a los turcos antes que someterse al culto católico» ${ }^{102}$. Y en este mismo sentido, «¿no es un rechazo, del mismo orden en ciertos aspectos, que el del comunismo en los países avanzados del capitalismo actual, Alemania, Inglaterra, los Estados Unidos? Nosotros, países católicos, estamos más abiertos a las ideologías marxistas, a las reivindicaciones igualitarias, al desprecio pregonado, ya que no practicado, de la riqueza. Si el lenguaje y las antiguas raíces de las civilizaciones no están en cuestión, ¿quién nos lo explicará? Todo esto viene de muy lejos» ${ }^{103}$.

Esta labor de aceptación o de rechazo practicada por una civilización frente a otras exteriores, se realiza también lentamente en su interior. «Casi siempre, la selección es poco consciente o prácticamente inconsciente. pero, poco a poco y gracias a esa selección, una civilización va transformándose, 'separándose' de una parte de su propio pasado» ${ }^{104}$. De entre la masa de bienes y de actitudes que su pasado y sus desarrollos le ofrecen, una civilización iría entresacando poco a poco, apartando y favoreciendo a unos sí y a otros no, hasta el momento en que adoptaría, por la selección hecha, un aspecto nunca enteramente nuevo, pero tampoco absolutamente igual. «Estas repulsas internas pueden ser francas, mitigadas, duraderas o pasajeras. Sólo los rechazos duraderos resultan esenciales en este terreno, progresivamente aclarado por los estudios de historia psicológica, cuando alcanzan las dimensiones de un país o de una civilización» ${ }^{105}$. Recoge Braudel, por ejemplo, los dos trabajos pioneros de Alberto Tenenti, sobre la vida y la muerte de los siglos XV y XVI, o el estudio sobre $L a$ idea de felicidad en Francia en el siglo XVIII de R. Mauzi, o el libro de Michel Foucault sobre la Historia de la locura en la edad clásica. «En los

${ }^{102} \mathrm{~F}$. Braudel, El Mediterráneo y el mundo mediterráneo en la época de Felipe II, op. cit., II, p. 157.

${ }^{103}$ F. Braudel, Escritos sobre la historia, op. cit., p. 139 y s.

${ }^{104} \mathrm{~F}$. Braudel, Las civilizaciones actuales, op. cit., p. 38 y s.

${ }^{105}$ Op. cit., p. 39.

«CUADERNOS DE ESTUDIOS GALLEGOS», Tomo L, Fascículo 116, Santiago 2003. 
tres casos -nos dice Braudel- se trata de un trabajo de uno mismo sobre sí mismo, de una civilización sobre ella misma, trabajo que pocas veces se realiza a la luz del día. Todo sigue una marcha tan lenta, que sólo excepcionalmente los contemporáneos son conscientes de ella. En cada caso, las eliminaciones - con las añadiduras que a veces provocan- tardan siglos en realizarse a causa de los vetos y de los obstáculos que encuentran, de las difíciles cicatrizaciones, con frecuencia incompletas, pero siempre muy lentas ${ }^{106}$.

Una vez más Braudel se decide por hacer un hueco en su pensamiento a los estudios e investigaciones que desde fuera de la disciplina estrictamente historiográfica se realizan y que puedan aportar algo de luz a los problemas con que se encuentra como historiador. En este caso concreto, la ayuda proviene de un filósofo-historiador que no tardaría mucho en alcanzar altas cotas de popularidad en su país y en el mundo entero. Nos referimos a Michel Foucault. La Historia de la locura en la edad clásica, Michel Foucault estudia un caso particular: la separación entre razón y locura, entre locos y sensatos, separación desconocida en la Edad Media europea, en la que el loco, como cualquier otro hombre desdichado, era más o menos considerado como un enviado de Dios. Sólo se encerrará por primera vez a los dementes, dura y brutalmente, en el siglo XVII, siglo enamorado del orden social, y que considera a los locos como unos seres molestos que deben ser expulsados del mundo, lo mismo que se rechaza a los delincuentes y a los vagabundos; después se les encierra con dulzura, incluso con un cierto cariño, durante el siglo XIX, que reconoce a los locos su calidad de enfermos. Entre ambas actitudes, el problema central continúa siendo el mismo: desde la edad clásica hasta nuestros días, el Occidente ha «apartado» de sí a la locura, ha proscrito su lenguaje y ha rechazado su presencia. De esta manera, el triunfo de la razón sigue en profundidad los pasos de una tempestad larga y silenciosa, de una gestión casi inconsciente y casi ignorada, y que es, sin embargo, en cierta manera la compañera de esta victoria que se ha obtenido a la luz del día, a saber: la conquista del racionalismo y de la ciencia clásica.

Foucault denomina en su terminología particular se partager, es decir, al hablar de una civilización, rechazar fuera de sus fronteras y de su vida

${ }^{106}$ Ibid.

«CUADERNOS DE ESTUDIOS GALLEGOS», Tomo L, Fascículo 116, Santiago 2003. 
un determinado valor del que ha renegado. «Es posible -escribe M. Foucault- hacer una historia de los límites, de los gestos oscuros, necesariamente olvidados, en cuanto se han realizado, a través de los cuales una civilización rechaza algo que se convierte en su Exterior; y, en el curso de la historia, este vacío, este espacio en blanco por el que se ha aislado, representa a la civilización al igual que sus valores peculiares. Porque estos valores los recibe y los mantiene en la continuidad histórica; pero en esta región de la que queremos hablar, realiza sus selecciones esenciales, realiza el reparto (somos nosotros los que subrayamos) que le confiere su aspecto positivo; es aquí donde se encuentra el espesor originario en el que se forma» ${ }^{107}$. A juicio de Braudel, «este texto, tan bello, merece ser leído y releído. Una civilización sólo alcanza su verdad personal al rechazar lo que la molesta en la oscuridad de las tierras limítrofes y ya extranjeras. Su historia es la decantación, a lo largo de los siglos, de una personalidad colectiva, encajada, como toda personalidad individual, entre un destino consciente y claro y un destino oscuro e inconsciente, que sirve de base y de motivación al primero, aunque no siempre se da a conocer» ${ }^{108}$.

Otro ejemplo de estas «separaciones» o «semiseparaciones» lo constituye, para Braudel, un libro de Alberto Tenenti ${ }^{109}$, que sigue minuciosamente el proceso por el cual Occidente se ha «separado» de la muerte cristiana tal como la había concebido la Edad Media, es decir, como un simple tránsito de la criatura, que está exiliada en la tierra, de la verdadera vida del más allá. En el siglo XV, la muerte se va «humanizando», se convierte en la prueba suprema del hombre, dominado por el horror de la descomposición del cuerpo. Pero, en esta concepción nueva de la muerte, el hombre encuentra una nueva concepción de la vida que, a sus ojos, recobra todo su precio y todo su valor humano. En el siglo XVI, que al menos en sus principios es el siglo de la alegría de vivir, desaparece una cierta obsesión por la muerte.

${ }^{107}$ Cit. por F. Braudel, Las civilizaciones actuales, op. cit., p. 39.

${ }^{108}$ F. Braudel, Las civilizaciones actuales, op. cit., p. 39.

${ }^{109}$ A.Tenenti, Sens de la mort et amour de la vie. Renaissance en Italie et en France, París, 1983 ( $2^{\mathrm{a}}$ ed.).

«CUADERNOS DE ESTUDIOS GALLEGOS», Tomo L, Fascículo 116, Santiago 2003. 


\section{BALANCE FINAL}

Si tuviésemos que escoger un pensamiento clave en la obra de Braudel, sin duda, sobre todo teniendo en cuenta la importancia concedida al concepto de «longue durée», sería este: «¿no limita acaso esa larga duración (no digo que suprima) a la vez la libertad y la responsabilidad de los hombres? Pues los hombres no hacen en modo alguno la historia, sino que es la historia, sobre todo ella, la que hace a los hombres y, en consecuencia, los declara inocentes». La sociedad braudeliana es conservadora, niega la capacidad del hombre para cambiar el curso de los acontecimientos, $y$, sobre todo destaca la inutilidad histórica de las revoluciones políticas y sociales ante la evidencia de que, después de todo, pase lo que pase, la desigualdad humana es una estructura de larga duración. ¿Qué es lo mejor? Propone Braudel participar en esta especie de selección de las especies en que se termina convirtiendo la historia. Domina o te dominarán. ¿Pertenece usted a un grupo social o a una civilización dominada, con problemas? ¿Vive en una época crítica? Tenga paciencia. ¿Comprueba usted que se está pecando de incomprensión hacia otras civilizaciones? No se preocupe. Siempre ha sido así. Y además, la incomprensión es mutua. ¿Que España expulsa a los judíos y a los moriscos? Existían motivos económicos, se trataba de su destino y además estaba buscando su identidad. ¿Que fue injusta la colonización europea de África? Sí, pero la aportación europea, a pesar de haber roto el equilibrio social de estos pueblos, fue más importante. ¿Que se llena Francia de inmigrantes? Bueno, si son inmigrantes de calidad, pase. Los otros, los desheredados, pueden traer a Francia guerras de religión, de las que los franceses no tienen necesidad ${ }^{110}$. Además, sepa usted, por ejemplo, que el pueblo ruso es un pueblo tradicionalmente indolente ${ }^{111}$, que los australianos son jugadores y bebedores ${ }^{112}$, que no hay nadie que hable tan mal de su país como un francés ${ }^{113}$.

\footnotetext{
${ }^{110} \mathrm{He}$ publicado varios trabajos sobre todos estos aspectos. Cf. J. R. Goberna Falque, «La cofradía de los historiadores. Estudio de los mecanismos institucionales y sociales de la escuela de los 'Annales' durante la era Braudel», Historia y Crítica, IV, 1994, pp. 85-120; «El 'choque de civilizaciones' en la concepción braudeliana de la Historia», Minius, $\mathrm{n}^{\circ}$ IX, 2001, pp. 197-214; y «Fernand Braudel y las ciencias sociales», Cuadernos de Estudios Gallegos, 2002, (en prensa).

${ }^{111}$ F. Braudel, Las civilizaciones actuales, op. cit., p. 480.

${ }^{112}$ Op. cit., p. 454 y s.

${ }^{113}$ F. Braudel, Escritos sobre la historia, op. cit., p. 173.
}

«CUADERNOS DE ESTUDIOS GALLEGOS», Tomo L, Fascículo 116, Santiago 2003. 
La pasión, esa pasión que Braudel pretendía mantener apartada en $L a$ Identidad de Francia, está presente a lo largo de toda su obra, por mucho que él intente evitarla: «Amo a Francia con la misma pasión, exigente y complicada, que sentía Jules Michelet; sin distinguir entre sus virtudes y sus defectos, entre lo que prefiero y lo que acepto menos fácilmente. Pero esa pasión no tendrá cabida en las páginas de este libro. La mantendré cuidadosamente apartada... El oficio de historiador nos condena cada vez más a la sequedad, a la exclusión del corazón» ${ }^{114}$. Esta otra cita va en el mismo sentido: «Uno debe purgarse pues de sus pasiones, aquellas que proceden de nuestro ser, de nuestra posición social, de nuestras experiencias, de nuestras explosiones de indignación o de nuestros entusiasmos, de nuestras 'ecuaciones personales', del desarrollo mismo de nuestra vida, de las múltiples insinuaciones de nuestra época» ${ }^{115}$. Sin embargo, más tarde matiza esta afirmación: «¿cómo mantener apartada la moral? La moral interviene espontáneamente, lógicamente, en el campo mismo de la observación. En matemática, evidentemente no hay moral. En física hay apenas algunas zonas peligrosas... aunque muy peligrosas. En biología, la moral no cesa de gruñir y no ha terminado de hacerlo. En las ciencias sociales es peor aún: la moral levanta el tono de la voz sobre todo si tiene uno la imprudencia de abordar lo actual o lo que pueda acontecer en el futuro. La historia de antaño, ipase! La historia de hoy o la de mañana es algo sobre lo que cada uno cree que tiene algo que decir. La moral, nuestras morales, están pues presentes en el debate. No lograré hacer que se larguen. A lo sumo trataré de que se mantengan en su lugar» ${ }^{116}$. En último caso, Braudel confiesa su debilidad: «No debía, y lo digo con toda sinceridad. Pero tengo nostalgia de la grandeza de Francia $»^{117}$. La escritura de la historia, y el uso de conceptos del discurso histórico, como el concepto de civilización, oculta tras de sí una estructura catóptrica en la que la imagen difusa del historiador se muestra reflejada. Braudel no es más que un ejemplo.

${ }^{114}$ F. Braudel, La Identidad de Francia, op. cit., I, p. 13.

${ }^{115}$ Op. cit., I, p. 14.

${ }^{116}$ Op. cit., II, p. 181.

${ }^{117}$ VV. AA., Una lección de historia de Fernand Braudel, México, Fondo de Cultura Económica, 1989 (París, 1986), p. 209.

«CUADERNOS DE ESTUDIOS GALLEGOS», Tomo L, Fascículo 116, Santiago 2003. 